\title{
A politização dos desastres naturais: alinhamento partidário, declarações de emergência e a alocação de recursos federais para os municípios no Brasil
}

\author{
Anderson Henrique ${ }^{1}$ (D) \\ Mariana Batista ${ }^{2}$ (iD
}

\begin{abstract}
Qual a relação entre o alinhamento partidário e a alocação de reconhecimento e recursos federais emergenciais para os municípios brasileiros? Propomos que, mesmo sendo os desastres dados pela natureza, a política importa para o reconhecimento federal e o valor em transferências recebido. $O$ argumento é que o governo beneficiará os prefeitos alinhados, reconhecendo as declarações de emergência e alocando mais recursos para os municípios do mesmo partido. Considerando o presidencialismo de coalizão brasileiro, testamos três hipóteses para o alinhamento político: alinhamento com o presidente, com a coalizão e com o ministro da Integração Nacional. Apresentamos um banco de dados original com as declarações de emergência para os municípios e os valores transferidos para esse fim no período de 2010 a 2015 . Utilizamos modelos de regressão de Poisson e um modelo em duas partes para testar nossas hipóteses. Os resultados indicam que as declarações são reconhecidas e as transferências de emergência são alocadas de forma a beneficiar os aliados políticos no nível subnacional, em especial os prefeitos alinhados ao ministro da Integração Nacional.
\end{abstract}

Palavras-chave: desastre natural; presidencialismo de coalizão; declarações de emergência; transferências federais de emergência

\section{Introdução}

Desastres naturais são situações nas quais um fenômeno natural gera impacto extremo sobre um sistema social, causando danos e prejuízos. Esses desastres podem ser causados por razões climáticas, como secas, temperaturas extremas e tempestades, ou ainda por razões hidrológicas, como inundações ou enchentes. Podem ser também gerados por razões biológicas, como epidemias, e por razões geofísicas, como terremotos e vulcões.

\footnotetext{
1 Universidade Federal de Pernambuco Departamento de Ciência Política. Recife (PE), Brasil. E-mail: <anderson.hsilva@ufpe.br>.

2 Universidade Federal de Pernambuco, Departamento de Ciência Política. Recife (PE), Brasil.

E-mail: <mariana.bsilva@gmail.com>.
} 
Enquanto a última situação não é observada no Brasil, as demais o são em maior ou menor grau. Entre 2008 e 2012, cerca de 40,9\% dos municípios brasileiros sofreram com pelo menos um desastre natural, deixando cerca de 1.406 .713 pessoas desalojadas ou desabrigadas em todo o país (IBGE, 2014). Essa situação levou os municípios a decretarem emergência. Entre 2000 e 2017, foram reconhecidas pelo governo federal 6.164 situações de emergência em 2.872 municípios, correspondendo a 51,5\% do total de governos locais (Brasil, 2018).

O reconhecimento federal da situação de emergência ou de calamidade gera contexto jurídico especial, no qual os municípios podem desburocratizar processos para ação mais rápida, como a contratação de serviços sem licitação. Além disso, o reconhecimento federal de situação de emergência gera acesso a recursos do governo federal que podem ser alocados por meio de transferências do Ministério da Integração Nacional. Dessa forma, tanto o reconhecimento federal quanto a alocação de transferências de emergência seriam recursos valorizados pelos municípios. Porém, a relação entre oferta e demanda por recursos se dá de forma neutra ou a política importa nesse contexto? Isto é, a ação do governo federal na alocação de recursos é uma resposta direta a uma demanda gerada de forma exógena pela natureza ou há direcionamento político?

Podemos analisar o reconhecimento federal da declaração de emergência e o uso das transferências de emergência como instrumentos de política distributiva, que podem ser alocados pelos atores políticos para beneficiar os aliados partidários ou por razões eleitorais. Políticas distributivas são caracterizadas pelo impacto geograficamente concentrado e pela facilidade de identificação dos beneficiários (Lowi, 1964). Dessa forma, o governo federal pode "discriminar" os solicitantes de recursos, de forma a beneficiar o seu próprio partido e prejudicar os opositores (Fenno, 1978; Cox e McCubbins, 1986; Rich, 1989).

No contexto das declarações de emergência e do envio de transferências federais emergenciais, estudos sugerem que, apesar de os desastres naturais serem exógenos, a reação ao desastre é de controle dos gestores. Dessa forma, o envio dos recursos pode ter caráter político, além de ser um dos instrumentos usados pelo Executivo federal para enfraquecer a oposição e reforçar a posição política dos seus copartidários e apoiadores sistemáticos (Downton e Pielke, 2001; Stehr, 2006; Reeves, 2011; Kriner e Reeves, 2015; Kumar, 2016). Dessa forma, buscamos aqui identificar se o reconhecimento federal da situação de emergência e as transferências emergenciais são usadas politicamente através da discriminação sistemática entre governo e oposição. Nosso foco está nos municípios brasileiros, assim, analisamos a relação entre o alinhamento partidário do prefeito com o governo federal e a declaração de emergência e a alocação de transferências federais emergenciais.

No presidencialismo de coalizão observado no Brasil no período analisado, os governos são multipartidários e estabelecem o compartilhamento do poder. Dessa forma, as decisões de alocação de recursos são tomadas não somente pelo presidente, mas 
também pelos ministros das pastas setoriais que são indicados pelos parceiros da coalizão. Considerando essa complexidade do arranjo institucional brasileiro, verificamos não somente se a declaração e as transferências são politicamente orientadas, mas também qual o ator político do governo federal a cujas preferências elas respondem. Analisamos, então, a relação do alinhamento partidário do prefeito com o presidente, com os partidos da coalizão e com o ministro da pasta responsável pela declaração e pelas transferências (Ministério da Integração Nacional - MI).

Portanto, qual a relação entre o alinhamento partidário e a alocação de reconhecimento e recursos federais emergenciais para os municípios brasileiros? Analisamos então o reconhecimento formal da situação de emergência pelo governo federal e a alocação de recursos por meio de transferências para os municípios brasileiros afetados por desastres no período de 2010 a 2015. Testamos nossas hipóteses por meio de análise quantitativa. Os resultados indicam que a declaração e as transferências de emergência são utilizadas como instrumento de política distributiva e beneficiam sistematicamente os municípios alinhados, em especial, ao ministro do MI. A análise aqui desenvolvida contribui para a literatura sobre política distributiva e alocação de recursos públicos, mostrando que fatores políticos importam para a definição de quem ganha o quê, mesmo em situações de emergência.

Assim, para fins de estruturação, este artigo está dividido nas seguintes seções: A primeira, "Desastres naturais, declarações de emergência e transferências intergovernamentais", apresenta uma discussão acerca das características para estabelecer as declarações de emergência e o envio de transferências intergovernamentais relacionadas a desastres. A segunda seção, "Quem ganha o quê? A política das transferências federais", dispõe sobre os principais estudos relacionados à política distributiva e suas implicações. Na seção seguinte, "Argumento", discorremos sobre o argumento do artigo e as hipóteses. Em seguida, em "Metodologia", temos a estratégia empírica adotada para testar as hipóteses levantadas. Em "Resultados", por sua vez, mostramos os principais achados das análises estatísticas dos modelos propostos. Por fim, na última seção, "Conclusão", apresentamos as considerações finais.

\section{Desastres naturais, declarações de emergência e transferências intergovernamentais}

Desastre natural é um fenômeno que modifica todo o ecossistema de uma região e produz prejuízos econômicos e humanos. A Defesa Civil no Brasil, órgão ligado ao Ministério da Integração Nacional, define desastre como "o resultado de eventos adversos, naturais ou antrópicos, sobre um território ou ecossistema, causando danos humanos, materiais ou ambientais e consequentes prejuízos econômicos e sociais" (Brasil, 2018, p. $1)$. 
Geralmente, os governos buscam ter ferramentas e agências responsáveis por criar ações rápidas para reparar ao máximo os danos causados através de auxílios financeiros, humanitários e estruturais. No Brasil, o órgão do governo destinado a essa função é o Ministério da Integração Nacional, que, através do Sistema Nacional de Defesa Civil (Sedec) e com auxílio das Defesas Civis dos estados e municípios, aloca recursos de transferências extraordinárias de Emergência e Calamidade Pública para auxiliar a reconstrução de estados e municípios atingidos.

Esses recursos pós-desastres podem ser alocados através de transferências voluntárias ou obrigatórias. O que diferencia a aplicabilidade de uma modalidade ou outra é o momento de solicitação dos recursos: a transferência obrigatória deve ser requerida dentro do prazo estipulado pela Lei n 12.340/2010 (Brasil, 2011).

Em especial, essa lei estabelece a criação das Transferências Obrigatórias Emergenciais (ou Transferências Federais de Emergências) da União aos demais órgãos e entes federados, como estados, Distrito Federal e municípios, para a execução de ações de prevenção em áreas de risco e atingidas por desastres naturais. Através do Fundo Nacional para Calamidades Públicas, Proteção e Defesa Civil (Funcap), a União define os montantes de recursos a serem transferidos, decorrentes das ações que os entes solicitantes responsáveis poderão executar de acordo com o plano de trabalho apresentado ao Ministério da Integração Nacional (MI) e encaminhado através do Sistema Integrado de Informações sobre Desastres (S2ID) ${ }^{3}$.

Em norma complementar, o Decreto $n^{\circ} 7.257 / 2010$ estabelece critérios para o reconhecimento pelo Poder Executivo federal da situação de emergência e calamidade pública ${ }^{4}$. Entre alguns critérios, é dever dos Executivos estaduais, do Distrito Federal e dos municipais afetados pelo desastre: terem estado de emergência decretados, apresentarem junto ao MI documentações específicas da solicitação de socorro, terem sua situação federal de emergência reconhecida e se enquadrarem na elegibilidade para receber os recursos de emergência. Nesse contexto, nem todos os municípios atingidos recebem auxílio financeiro federal obrigatório por, muitas vezes, não atenderem aos requisitos mínimos exigidos.

Só após feito o reconhecimento federal, com o auxílio do plano de trabalho de recuperação dos locais atingidos e dos demais documentos complementares solicitados, são enviados os recursos obrigatórios emergenciais necessários ${ }^{5}$. As transferências

\footnotetext{
3 O S2ID é um sistema pelo qual estados, municípios e Distrito Federal se cadastram para solicitar o reconhecimento federal para situação de desastre ou estado de calamidade pública.

4 Para melhor entendimento dos termos "Situação de Emergência" e "Estado de Calamidade Pública", o Decreto $n^{\circ} 7.257 / 2010$, no artigo 1, define ambos como "situação anormal, provocada por desastres, causando danos e prejuízos que impliquem o comprometimento parcial da capacidade de resposta do poder público do ente atingido" (Brasil, 2010). Neste artigo, trataremos ambos os conceitos para motivação de envio de recursos constitucionais de emergência como sinônimos. Para mais informações, ver <http://www.planalto.gov.br/ccivil_03/_Ato2007-2010/2010/Decreto/D7257.htm>. Acesso em: 6 dez. 2018.

${ }^{5}$ Segundo orientações do MI (Brasil, 2011), na modalidade de Transferência Federal de Emergência, a análise e a aprovação pela Sedec dos orçamentos serão posteriores à liberação dos recursos. Podendo eventuais
} 
federais de emergência têm como objetivo primordial a execução de ações de socorro, assistência às vítimas, restabelecimento de serviços essenciais e reconstrução de locais atingidos por desastres naturais.

Assim, em linhas gerais, o papel do MI é (1) estabelecer diretrizes de ações de prevenção em áreas de risco e de recuperação em áreas atingidas por desastres, (2) receber e avaliar o pedido de auxílio emergencial, levando em consideração a elegibilidade e o plano de trabalho apresentados pelos solicitantes, (3) alocar os recursos em parcela única ou em até duas etapas em nome do órgão ou entidade do estado, do município e do Distrito Federal, podendo conceder mais recursos caso solicitado pelo ente e analisado pelo ministério, (4) fiscalizar e acompanhar a execução das metas dos planos de trabalho elaborados, através de visitas técnicas, solicitando auditorias dos orçamentos pelo Tribunal de Contas da União (TCU), caso necessário, e (5) receber a prestação total de contas dos entes beneficiários das transferências recebidas.

Dessa forma, numa situação de desastre natural, o município que decretar emergência pode solicitar duas formas de atuação do governo federal. A primeira é o reconhecimento federal da situação de emergência. Esse reconhecimento formal traz como benefício uma situação jurídica especial na qual os municípios podem agir com maior rapidez, evitando processos burocráticos, como licitações para contratação de serviços públicos.

A segunda forma de atuação governamental, que usualmente segue o reconhecimento formal da situação de emergência pelo governo federal, é a alocação de transferências federais para ajudar diretamente na prevenção e na recuperação de áreas atingidas por desastres. Essas transferências de emergência são dispositivos extraordinários obrigatórios da União aos entes federados, importantes para o auxílio imediato aos locais atingidos por desastres naturais, na medida em que fornecem capacidade orçamentária para os prefeitos tratarem seus problemas mais patentes provenientes do pós-desastre natural.

O desastre natural pode ser considerado um evento exógeno e estocástico (Healy e Malhotra, 2009). Não são causados ou controlados pelos atores políticos. Contudo, a resposta ao desastre é uma ação política por natureza, uma vez que desastres demandam intervenção pública (Reinhardt e Ross, 2019). Nesse contexto, o reconhecimento formal da situação de emergência e a alocação de transferências federais para os entes atingidos são decisões dos atores políticos do Poder Executivo federal, entre estes principalmente o presidente da República, o gabinete ministerial e o ministro responsável pela pasta de Integração Nacional. Esses atores políticos têm preferências, objetivos e estratégias de sobrevivência política particulares. Dessa forma, perguntamo-nos se a política importa para a alocação de recursos de transferências federais de emergência.

irregularidades detectadas (como projeto deficiente ou sobrepreço) implicar a devolução de recursos no âmbito do Tribunal de Contas da União (TCU), a inadimplência e a responsabilização pessoal do gestor solicitante. 


\section{Quem ganha o quê? A política das transferências federais}

A alocação de recursos públicos de forma individualizada e geograficamente concentrada é uma estratégia relevante para os atores políticos na construção de apoio e na sobrevivência eleitoral. A política, como definiu Laswell (1936), é a definição de quem ganha o quê, quando e como, e por essa razão a análise da política distributiva se tornou central.

A literatura sobre política distributiva, isto é, políticas que apresentam custo difuso e benefício concentrado e que são claramente identificáveis (Lowi, 1964), é ampla e diversa6. O objetivo é identificar em que medida os atores políticos são capazes de influenciar a alocação de recursos dados os seus objetivos políticos. A maior parte dessa literatura elege o Legislativo como arena política de interesse e os membros das comissões legislativas e do partido majoritário como atores fundamentais na alocação de recursos públicos. Contudo, análises mais recentes têm incorporado também o papel do presidente na política distributiva.

Os estudos sobre política distributiva buscam mostrar as razões políticas por trás da repartição de recursos. Dado que os políticos buscam sobrevivência política, para quem esses recursos seriam alocados? Quais são os incentivos políticos para os atores nacionais e locais e qual padrão de alocação gerariam? Nesse ponto a literatura sobre política distributiva se divide em dois argumentos principais. O primeiro visa os eleitores e seu padrão de votação e o segundo, as elites políticas e a disputa por crédito na implementação dos recursos (Bohlken, 2018).

Para o primeiro modelo, o foco principal está nas características dos eleitores. Como os atores políticos alocam recursos com o objetivo de sucesso eleitoral, e, como esses recursos são escassos, esses atores precisam decidir quais eleitores beneficiar. Isto é, qual estratégia é mais eficiente. A primeira estratégia é alocar recursos para os eleitores que já são apoiadores sistemáticos. Essa é a estratégia de beneficiar os core voters (Cox e McCubbins, 1986). Uma outra estratégia parte do pressuposto de que os eleitores podem ser "comprados" através da alocação de recursos. Assim, os políticos buscariam trazer os eleitores da oposição. De acordo com o argumento, os eleitores mais próximos do centro seriam mais visados já que mudariam de posição mais facilmente do que um eleitor no extremo oposto, ou seja, seriam mais "baratos". Esses são os swing voters (Dixit e Londregan, 1996).

A disputa entre os modelos de core voter e swing voter animou a literatura empírica sobre política distributiva, principalmente nos Estados Unidos, e os resultados tendem a favorecer a hipótese dos swing voters (Golden e Min, 2013). Contudo, a maior parte dos trabalhos que usam esses conceitos acaba por aplicá-los empiricamente de forma equivocada. Isso porque o embate core x swing se refere a eleitores e não a distritos

\footnotetext{
${ }^{6}$ Não é o objetivo do presente artigo oferecer uma revisão de literatura exaustiva sobre esse tema, que deve ser um dos mais prolíficos na política comparada. Para uma revisão sistemática, ver Golden e Min (2013).
} 
eleitorais. Dessa forma, o teste efetivo dos argumentos requer dados de survey com eleitores, e não dados agregados de percentual de votos num determinado distrito eleitoral (Cox e McCubbins, 2010; Golden e Min, 2013).

Um desenvolvimento desse debate seria o foco nos distritos eleitorais mais competitivos, ou distritos battleground. Esses são distritos que, devido à competitividade da eleição, podem pender tanto para um lado quanto para o outro, considerando a competição entre dois partidos. A característica de "o vencedor leva tudo" do colégio eleitoral americano faz com que esses distritos sejam os mais importantes para definir o resultado da eleição e por isso seriam o alvo primordial na alocação de recursos.

Alguns achados empíricos recentes dessa literatura rejeitam explicitamente o chamado "universalismo presidencial", que prevê que os presidentes alocarão recursos de forma imparcial uma vez que são representantes nacionais e não locais. Reeves (2011) analisa o poder unilateral do presidente de decidir sobre declarações de desastre, mostrando que os presidentes direcionam mais recursos para estados mais competitivos ou os battleground states. Em estudo sobre o Brasil, Litschig (2012) mostra que mesmo transferências baseadas em fórmula, e que por essa razão deveriam ser blindadas de influência política, são direcionadas politicamente. Os resultados indicam o direcionamento de recursos para os estados com eleições mais competitivas.

O segundo modelo visa as características dos atores políticos em diferentes poderes ou diferentes níveis do governo e como disputam o crédito pela implementação de recursos públicos. O argumento é que muitas vezes os recursos passam por diferentes níveis de governo, desde o governo federal até a entrega das políticas públicas pelos governos locais, passando pela relação Executivo-Legislativo. Dado que a implementação de recursos gera benefícios eleitorais para os governantes, o presidente busca formas de reclamar o crédito pela alocação de recursos ao mesmo tempo que beneficia os governantes locais alinhados politicamente e nega à oposição acesso a esses recursos. Em suma, o presidente decide sobre a alocação de recursos de forma a maximizar a sua chance de reclamar o crédito e, assim, se beneficiar eleitoralmente, e também de forma a recompensar os apoiadores sistemáticos e aliados políticos. A priorização dos aliados políticos pode ter por base a construção de apoio horizontal ao beneficiar distritos controlados por deputados e senadores do mesmo partido, ou a construção de apoio vertical, ao beneficiar governadores e prefeitos alinhados (Berry, Burden e Howell, 2010).

Algumas análises empíricas mostram o efeito do alinhamento político sobre o direcionamento de recursos públicos. Berry, Burden e Howell (2010), em análise pioneira sobre a política distributiva dos presidentes, mostram que as localidades recebem sistematicamente mais recursos do governo federal quando são representadas por legisladores do partido do presidente, evidenciando o efeito do alinhamento horizontal. Brollo e Nannicini (2012) encontram que, no Brasil, prefeitos alinhados com a coalizão de governo em geral e com o partido do presidente em particular são beneficiados na alocação 
de recursos federais. De forma complementar, os municípios com prefeitos da oposição são prejudicados recebendo menos recursos.

Alguns estudos abordam, além dos interesses políticos, também a preocupação com o bem-estar dos cidadãos ou a qualidade das políticas públicas. Bueno (2018) parte do pressuposto de que os presidentes são governantes "quase benevolentes" e que se preocupam com os resultados políticos, mas também, em alguma medida, com o bemestar de seus eleitores. A autora mostra que a forma encontrada pelos presidentes brasileiros para beneficiar os eleitores, mas sem permitir que prefeitos da oposição reclamem o crédito pelas ações, é a transferência de recursos numa rota alternativa que não passa pelas prefeituras e é implementada por provedores não estatais, como organizações da sociedade civil. Bohlken (2018), por sua vez, propõe uma lógica de cooperação entre elites de modo que o presidente aloque recursos para alinhados partidários como uma forma de assegurar que os projetos de desenvolvimento sejam implementados de acordo com as preferências dos representantes nacionais.

Com foco na perspectiva dos eleitores, Healy e Malhotra (2009) mostram evidência de que os eleitores tendem a recompensar os presidentes quando estes alocam recursos para combater os efeitos de desastres naturais, e esses recursos são especialmente relevantes quando se referem a benefícios de alívio individual. Gallego (2018) chega aos mesmos resultados utilizando dados da Colômbia7. Gasper e Reeves (2011) mostram inclusive que os eleitores são capazes de distinguir entre o presidente e os governadores e entre a intenção de ajuda e a negação de apoio. Os autores mostram que, quando o governador solicita uma declaração de emergência e o presidente nega o pedido, o presidente é punido e o governador recompensado eleitoralmente. Essas análises que incluem a perspectiva dos eleitores mostram os incentivos sobre o comportamento dos políticos, que buscarão beneficiar os seus eleitores e colher os frutos eleitorais na próxima disputa.

O presente artigo se situa nesse segundo modelo de análise da política distributiva, visando a relação entre as elites políticas e como elas orientam sua estratégia para reclamar o crédito pela alocação dos recursos, priorizando os aliados partidários e punindo a oposição. O próximo tópico desenvolve a nossa perspectiva analítica.

\section{Argumento}

Analisar a política distributiva no Brasil requer atenção às características do desenho institucional do país. A mais marcante entre elas é o que ficou conhecido como "presidencialismo de coalizão" (Abranches, 1988). Essa definição advém da combinação

\footnotetext{
7 Sobre como os efeitos observados dependem do tipo de recurso analisado, ver Kramon e Posner (2013).
} 
entre o presidencialismo e o multipartidarismo e se constitui na regra observada entre 1995 e $2018^{8}$.

Para manter a sua agenda no Congresso, o presidente precisa construir apoio por meio de coalizões multipartidárias. A formação de governos multipartidários no presidencialismo teria a distribuição de cargos no gabinete como elemento central (Amorim Neto, 2006). Com a composição de um gabinete multipartidário, as pastas ministeriais são ocupadas por outros partidos, e não somente o do presidente. Isso gera maior complexidade para o processo decisório do Executivo, que agora precisa coordenar preferências e resolver problemas de ação coletiva. Isso porque as preferências do Executivo não são equivalentes às preferências do presidente no caso de um governo multipartidário.

Outra característica marcante do desenho institucional brasileiro é a predominância do Poder Executivo na formação da agenda e na relação entre o Executivo e o Legislativo (Figueiredo e Limongi, 2001). Essa predominância é especialmente marcante quando se considera a política distributiva. Isso ocorre porque no Brasil o Executivo é responsável pela formulação da peça orçamentária. Os legisladores podem oferecer emendas ao orçamento, mas essas alterações são restritas a uma parte menor do orçamento total. Mais importante, o Executivo detém o poder de executar o orçamento, e mesmo as emendas oferecidas pelos parlamentares necessitam de autorização do Executivo para sua efetiva implementação (Pereira e Mueller, 2002) ${ }^{9}$.

Por essas razões, a análise da política distributiva no Brasil tem sido muito focada no Executivo e no uso de recursos públicos para a construção de apoio político de forma horizontal. A análise tradicional visa o embate entre as diferentes visões sobre a importância da política distributiva. Alguns autores defendem a construção de apoio de forma individualizada através da execução de emendas parlamentares. Esse argumento seria comprovado com a priorização de parlamentares que oferecem apoio à agenda do Executivo na execução das emendas (Ames, 2001; Pereira e Mueller, 2002, 2003; Raile, Pereira e Power, 2011). Do lado oposto, Limongi e Figueiredo (2002, 2005) questionam a efetividade da estratégia de construção de apoio político "no varejo". De forma bastante contundente, Vasselai e Mignozzetti (2014) consideram vários problemas metodológicos nas estimativas anteriores, mostrando não haver relação discernível entre disciplina partidária e execução de emendas. Dessa forma, a alocação de emendas não parece ser guiada prioritariamente por esse critério individual de apoio político, sendo mais relacionada com o pertencimento à coalizão de governo.

\footnotetext{
8 Em 2019, Jair Bolsonaro assumiu o cargo de presidente e decidiu por não formar um governo de coalizão nos moldes observados até então. De toda forma, o período da gestão Bolsonaro não está incluído no presente artigo. Portanto, essa variação de arranjo não afeta nossas análises.

9 Em 2015, foi aprovada a Emenda Constitucional 86 que estabelece a execução obrigatória das emendas em montante correspondente a $1,2 \%$ da receita corrente líquida. Essa emenda aumentou a autonomia dos parlamentares e enfraqueceu o poder de barganha do Executivo, que perdeu influência sobre a execução das emendas (Baião, Couto e Oliveira, 2019).
} 
Análises mais recentes buscaram explorar o papel de outros atores na política distributiva. Batista (2015) estuda o papel dos ministros na alocação das emendas, mostrando haver um viés partidário na execução dos recursos particularistas. Esse papel dos ministros é revisitado por Baião, Couto e Jucá (2018), que analisam também o papel dos líderes e das normas fiscais para a política distributiva. Baião, Couto e Oliveira (2019) exploram o papel da "necessidade" por recursos para explicar a execução das emendas. Os autores mostram, considerando a área de saúde pública, que a política é determinante e que as emendas não são alocadas para os municípios que mais precisam, e sim para os que são alinhados.

Esse debate com foco nas emendas parlamentares é bastante desenvolvido no Brasil. Contudo, não somente de emendas se faz a política distributiva. A alocação de transferências federais também é um campo de atuação. Há evidências de que as transferências federais são alocadas prioritariamente por critérios políticos. Amorim Neto e Simonassi (2013) efetivamente refutam a hipótese do universalismo, mostrando a importância do alinhamento político. Já Arretche e Rodden (2004) encontram evidência a favor do favorecimento dos estados onde os eleitores foram apoiadores na última eleição. O efeito do alinhamento político com o presidente e também o papel da coalizão são apontados por Brollo e Nannicini (2012). O alinhamento partidário com os ministros também se mostra relevante (Batista, 2014; Meireles, 2019). Por último, o trabalho já citado de Bueno (2018) explora o papel de atores não estatais como uma forma de não favorecer os prefeitos da oposição.

Especificamente sobre a análise de recursos de emergência como política distributiva, Bastos e Miller (2013) mostram o efeito do alinhamento partidário sobre o reconhecimento federal da declaração de emergência pelos municípios brasileiros, e Cavalcanti (2018) analisa a chamada "indústria da seca" e mostra como o alinhamento partidário com o presidente aumenta o recebimento de recursos do tipo paliativo. 0 alinhamento não parece ter efeito sobre os recursos para medidas preventivas. Nosso artigo se insere nessa diminuta literatura sobre a alocação de recursos de emergência no Brasil e busca contribuir para a análise dos critérios políticos na decisão sobre recursos emergenciais.

Exploramos o efeito do alinhamento partidário sobre o reconhecimento das declarações de emergência e também sobre a alocação de transferências federais de emergência. Ressaltamos o papel central do Poder Executivo na alocação de transferências, em especial de emergência, que, devido ao caráter urgente, exclui a participação do Legislativo. Propomos a análise no nível municipal por esse nível oferecer maior variabilidade na composição política dos governos locais. Considerando o contexto institucional específico do Brasil, exploramos o papel do alinhamento partidário do prefeito com o presidente da República, com a coalizão de governo e com o ministro da pasta responsável pela alocação dos recursos públicos. 
O presidente é o ator central no processo decisório do Executivo, e, por essa razão, suas preferências devem ser consideradas na política distributiva do governo. Ele teria incentivos para alocar transferências federais para municípios governados pelo seu próprio partido como uma forma de garantir que os benefícios eleitorais aumentem suas próprias chances de reeleição, quando for o caso, de fazer o seu sucessor em caso de segundo mandato e também de fortalecer o seu partido nas disputas locais. Dessa forma, esperamos que o presidente influencie a alocação de recursos de forma a beneficiar os municípios governados pelo seu próprio partido. Por essa razão, esperamos que os municípios com prefeito do partido do presidente tenham maior chance de reconhecimento de situação de emergência e recebam mais recursos de transferências federais.

H1a: municípios alinhados ao partido do presidente têm mais chances de reconhecimento da situação de emergência.

H1b: municípios alinhados ao partido do presidente receberão mais recursos de transferências federais de emergência.

Contudo, dado o presidencialismo de coalizão, não somente as preferências do presidente são consideradas no processo decisório no âmbito de um gabinete multipartidário. Espera-se que, quando um partido decide fazer parte do governo, comprometendo-se com apoio à sua agenda legislativa, ele seja recompensado com acesso sobre as decisões governamentais e influência sobre elas, especialmente a política distributiva. Daí esperamos que os partidos da coalizão busquem alocar transferências para os municípios governados pelos seus partidos para também aumentar suas chances eleitorais.

H2a: municípios alinhados aos partidos da coalizão têm mais chances de reconhecimento da situação de emergência.

H2b: municípios alinhados aos partidos da coalizão receberão mais recursos de transferências federais de emergência.

O direcionamento de recursos para os municípios governados pelo partido do presidente e pelos parceiros da coalizão é esperado devido ao papel central do presidente num sistema presidencialista e também pela composição multipartidária dos gabinetes em governos de coalizão. Contudo, do ponto de vista administrativo, quem é mais diretamente responsável e tem maior potencial de influência sobre a decisão de reconhecimento de situação de emergência e a alocação de transferências para esse fim é o ministro da pasta, no caso do Brasil, o Ministério da Integração Nacional. Por essa razão esperamos que o ministro use o seu poder para influenciar as decisões e beneficiar municípios alinhados ao seu próprio partido.

H3a: municípios alinhados ao partido do ministro têm mais chances de reconhecimento da situação de emergência.

H3b: municípios alinhados ao partido do ministro receberão mais recursos de transferências federais de emergência. 
A atenção para o alinhamento partidário desses três atores centrais no processo decisório do Executivo nos dá a oportunidade de verificar se as situações de emergência são politizadas e também qual dos três atores - presidente, coalizão ou ministro - tem maior capacidade de extração de renda e de benefícios para os seus correligionários. Dessa forma, contribuímos tanto para a literatura sobre política distributiva quanto para a literatura sobre processo decisório do Executivo no Brasil.

De forma explícita, o nosso artigo inova em dois aspectos. Primeiro, analisamos a política distributiva na forma tanto das declarações de emergência quanto dos valores alocados pelo governo federal para os municípios brasileiros. Esse foco permite explorar a influência política em situações de choque exógeno e também comparar o efeito político tanto sobre a decisão de reconhecer a declaração de emergência quanto sobre os recursos de transferências federais alocados. Essa abordagem se diferencia de Bastos e Miller (2013), que analisam somente as declarações de emergência, e de Cavalcanti (2018), que analisa somente os recursos de combate à seca. Segundo, comparamos o efeito do alinhamento político explorando o papel do presidente, da coalizão e do ministro do MI nas decisões de política distributiva considerando recursos de emergência. Com isso, podemos explorar a dinâmica do Executivo no presidencialismo de coalizão brasileiro, mostrando quem influencia a distribuição de recursos de interesse para os municípios. O papel do presidente e da coalizão é explorado por Brollo e Nannicini (2012) e Bueno (2018), e o papel dos ministros, por Batista (2014) e Meireles (2019). Aqui exploramos a relação desses três tipos de alinhamento considerando os recursos de emergência.

Para além do alinhamento partidário, controlamos por alguns fatores relevantes para a declaração e a alocação de recursos de transferências de emergência. Primeiramente, consideramos o possível caráter redistributivo dessas transferências, já que os municípios que mais precisam seriam aqueles que deveriam ser mais beneficiados. Para tanto incluímos uma medida de vulnerabilidade social dos municípios como forma de controlar pela necessidade de recursos. Incluímos também o número de situações de desastre reportado pelo município. Considerando o primeiro modelo de análise da política distributiva, que é focado nos eleitores, controlamos também pelo percentual de votos para o partido do presidente e o estado do ministro. Controlamos ainda pelo fato de que, para solicitar os recursos, é necessário um grau de expertise técnica. Por isso, incluímos também a capacidade burocrática no artigo. Por último, considerando o efeito das eleições, incluímos indicador do ano eleitoral e do mandato do prefeito. Sobre o ano eleitoral, a expectativa é que a proximidade das eleições possa aumentar a demanda por recursos particularistas. Já sobre o mandato do prefeito, esperamos que prefeitos em segundo mandato, e que, portanto, não podem disputar a próxima eleição, reduzam a demanda por recursos particularistas. 


\section{Metodologia}

Para testar a relação entre o alinhamento com o governo e a distribuição de recursos de emergência, analisamos os municípios brasileiros no período de 2010 a 2015 . Dado que nem todos os municípios foram atingidos por desastres e, portanto, nem todos apresentam demanda por recursos do governo, nossas análises visam os municípios que reportaram algum desastre natural. A informação sobre os municípios que relataram desastre e o momento do ocorrido é disponibilizada no S2ID ${ }^{10}$. Dessa forma, a unidade de análise é o município-ano, mas só são incluídos nas análises os municípios que reportaram ao menos um desastre natural. No sistema, há informações de 18.605 desastres entre 2010 e 2015. Contudo, alguns municípios apresentam mais de um desastre natural. Por essa razão, nosso número de observações final é de 12.617 município-ano.

A variável independente principal do artigo é o alinhamento partidário do prefeito com o governo. A filiação partidária dos prefeitos foi coletada do site do Tribunal Superior Eleitoral (TSE). A identificação com o governo foi mensurada de três formas diferentes. Em todas, espera-se relação positiva entre o alinhamento e a alocação dos recursos de emergência.

"Alinhamento com o Presidente": mensura se o prefeito do local atingido pertence ao partido do presidente da República. Para o período da análise, os presidentes em questão foram sempre filiados ao Partido dos Trabalhadores (Luiz Inácio Lula da Silva e Dilma Rousseff). Essa constância no partido do presidente é uma das limitações do presente artigo, que somente poderá ser corrigida com a maior disponibilidade de dados.

"Alinhamento com a Coalizão": informa se o partido do prefeito faz parte da coalizão nacional. Os dados de composição da coalizão de governo foram disponibilizados pelo Cebrap no banco de dados legislativos. Para a categorização dos prefeitos em termos de alinhamento com a coalizão, utilizamos a coalizão que permaneceu no governo por mais tempo no ano em questão. Esse procedimento foi necessário porque algumas coalizões duraram apenas alguns poucos meses e os demais dados são disponibilizados anualmente.

"Alinhamento com o Ministro": testa a força do ministro da Integração Nacional em favorecer aliados políticos locais que pertencem ao mesmo partido. Utilizando os dados do Cebrap quanto à filiação partidária dos ministros, classificamos os prefeitos em duas categorias, aqueles que são do mesmo partido do ministro e os que não são. A análise do Ministério da Integração Nacional nesse caso foi especialmente relevante, porque se trata de um ministério tradicionalmente entregue a um parceiro da coalizão, e não a um membro do partido do presidente (Batista, 2018). Dessa forma, é possível dissociar o efeito do alinhamento ao partido do presidente do efeito do alinhamento ao partido do ministro.

Como variáveis de controle utilizamos:

\footnotetext{
10 Dados disponíveis em: <https://s2id.mi.gov.br/>. Acesso em: 30 abr. 2020.
} 
Vulnerabilidade Social: utilizamos a cobertura do Programa Bolsa Família no município como medida de vulnerabilidade da população. Medidas mais tradicionais de desenvolvimento, como o Produto Interno Bruto, podem não ser tão sensíveis à desigualdade social e pobreza, que, por sua vez, identificam quão vulnerável a população está e a ajuda que demandará no caso de um desastre natural. Os dados, cuja fonte é o Ministério do Desenvolvimento Social ${ }^{11}$, indicam o percentual da população do município beneficiada pelo Programa Bolsa Família (PBF).

Burocracia Comissionada: medida baseada na proporção de funcionários na administração pública local que são somente comissionados, isto é, não foram recrutados pelo serviço público (Batista, 2015; Marenco, 2017; Marenco, Strohschoen e Joner, 2017). A nomeação para o serviço público de pessoal não recrutado através de concurso público é normalmente considerada como politização da burocracia, uma vez que o recrutamento não seria meritocrático. Esperamos, então, que essa politização da burocracia, observada como a proporção de funcionários que são somente comissionados, e por isso não detêm estabilidade no cargo, diminua a capacidade burocrática do município. Isso implicaria menor capacidade de conduzir o processo formal de declaração de emergência e solicitação de recursos, que requer o conhecimento de muitos procedimentos burocráticos. Os dados são da pesquisa "Perfil dos municípios", conduzida pelo IBGE. Espera-se, nesse caso, um coeficiente negativo.

Reeleito: variável binária que assume o valor 1 quando o prefeito está no seu segundo mandato, isto é, foi reeleito, e o valor 0 quando o prefeito está no seu primeiro mandato. Os dados são da pesquisa "Perfil dos municípios" do IBGE. Incluímos reeleição para controlar pela expectativa de que prefeitos em segundo mandato não têm os incentivos eleitorais de disputa de uma nova eleição, que podem ser relevantes para a decisão do governo de alocar recursos para o referido município. Esperamos, então, um coeficiente negativo para o prefeito no segundo mandato.

Ano Eleitoral: variável que corresponde ao ano de eleição presidencial, pois a literatura aponta que em anos eleitorais existe maior favorecimento no envio de recursos intergovernamentais de emergência para reforçar a base do presidente e também lhe dar maior visibilidade. Espera-se um coeficiente positivo.

Votos Presidente: variável que indica o percentual de votos para o presidente na última eleição no município. Essa variável busca controlar pelo possível favorecimento pelo presidente de sua base eleitoral, direcionando recursos para aqueles municípios com maior percentual de apoiadores. Essa relação com o eleitor seria um caminho alternativo para a alocação de recursos, não passando pela identificação partidária com o prefeito da localidade. Espera-se um coeficiente positivo.

Estado Ministro: variável que indica se o município se localiza no estado de origem do ministro. Dado que ministros não são indicados para o cargo através de uma eleição

\footnotetext{
${ }^{11}$ Dados disponíveis em: <https://aplicacoes.mds.gov.br/sagi/vis/data3/data-explorer.php>. Acesso em: 30
} abr. 2020. 
majoritária, uma forma de identificar a relação entre esse ator e o seu potencial eleitorado é através da sua base eleitoral. Da mesma forma que esperamos que o presidente busque beneficiar o seu eleitorado, para além da identificação partidária com o prefeito, esperamos que o ministro busque beneficiar o eleitorado do seu estado, como forma de construir uma base eleitoral. Esperamos, então, um coeficiente positivo.

$N$ Desastres: variável que indica o número de situações de desastre reportadas pelo município em cada ano. Busca identificar a necessidade ou demanda dos municípios afetados por situações de desastre, e que podem ser inúmeras ao longo do ano. Os dados são do mesmo S2ID.

As variáveis dependentes da análise são duas: o reconhecimento formal da declaração de emergência e o valor alocado pelo governo federal em transferências emergenciais.

N Declaração de Emergência: variável que indica a contagem de reconhecimento de situações de emergência pelo município em cada ano. A variável assume a forma de contagem porque se mostra comum o reconhecimento de mais de uma situação de emergência em cada ano. Os dados são do Ministério da Integração Nacional.

Transferências Federais de Emergência: valor per capita em reais transferido para o município no ano. As transferências em questão pertencem à modalidade obrigatória. Os valores foram deflacionados pelo Índice Nacional de Preços ao Consumidor (IPCA) do IBGE para o ano-base de 2018. Municípios que não receberam transferências federais no ano obtêm o valor 0 . Os dados são do Ministério da Integração Nacional ${ }^{12}$.

Para o caso da primeira variável dependente, o número de reconhecimentos formais de declarações de emergência, a natureza de contagem da variável recomenda o uso de um modelo que se ajuste aos dados que apresentam somente valores inteiros e não negativos. Utilizamos, portanto, a regressão de Poisson, que se ajustou bem à distribuição dos dados. No segundo caso, a variável "transferências federais de emergência" pode ser considerada "semicontínua" e mostra uma distribuição bastante peculiar pois apresenta somente valores não negativos e com um pico no zero. Isso ocorre porque muitos municípios não receberam transferências federais e por isso assumem o valor 0 . Entre os que receberam transferências, há grande variação no valor recebido. Além disso, é possível que as duas situações sejam geradas por fatores diferentes. Isto é, num primeiro momento, temos que explicar quem recebe transferências federais e quem não recebe. Num segundo momento, explicamos o volume que os municípios receberam em transferências federais.

Para lidar com essa situação, optamos por estimar um modelo em duas partes. Esse modelo lida com a situação ao estimar, primeiramente, a probabilidade de recebimento de recursos pelo município através de um modelo de regressão logístico com efeitos mistos. Em seguida, condicional ao recebimento de recursos, é estimado o valor

12 Tabela com as estatísticas descritivas e com o número de observações para cada variável é apresentada nos "Anexos". 
recebido com o uso de um modelo log-normal, também com efeitos mistos. Os dois modelos são interligados com a estimação de efeitos aleatórios para os dois componentes, o logístico e o log-normal. Dessa forma, é permitido que os interceptos das duas regressões sejam correlacionados para evitar vieses nas inferências. Nas duas partes, as mesmas variáveis são incluídas no efeito fixo, e no efeito aleatório são incluídos interceptos por município. A estimação é feita usando Generalized Linear Mixed Models, com especificação da família Hurdle Log-Normal ${ }^{13}$. Nos "Anexos" apresentamos os resultados para a estimação dos modelos de forma independente, com uma regressão logística para a parte binária e uma regressão linear por mínimos quadrados ordinários para a parte contínua. Os resultados se mantêm os mesmos.

Ressaltamos que o desenho de pesquisa aqui implementado utiliza dados observacionais e, por essa razão, os resultados devem ser lidos com a cautela de associação entre as variáveis dados os controles especificados. Trabalhos futuros podem desenvolver os achados aqui apresentados com abordagens experimentais.

\section{Resultados}

No período de 2010 a 2015, os municípios brasileiros foram afetados por 18.605 situações que podem ser consideradas desastres naturais. Contudo, nem todos esses desastres obtiveram reconhecimento pelo governo federal. Este reconheceu formalmente 15.738 declarações de emergência dos municípios brasileiros. O número de declarações de emergência varia expressivamente por ano. No ano de 2010, foram 2.765 reconhecimentos de declaração de emergência municipal. Em 2011, a quantidade cai expressivamente para 1.282 declarações de emergência. O número volta a crescer em 2012, com 2.769, atingindo o valor máximo da série em 2013, com 3.745 declarações. A quantidade de declarações de emergência formalmente reconhecidas pelo governo federal cai novamente em 2014 e se mantém em 2015, com 2.666 e 2.511 declarações, respectivamente, como podemos ver na Figura 1.

13 Todas as estimações foram feitas com uso do R, com o pacote GLMMadaptive. 
Figura 1

Declarações de emergência reconhecidas pelo governo federal

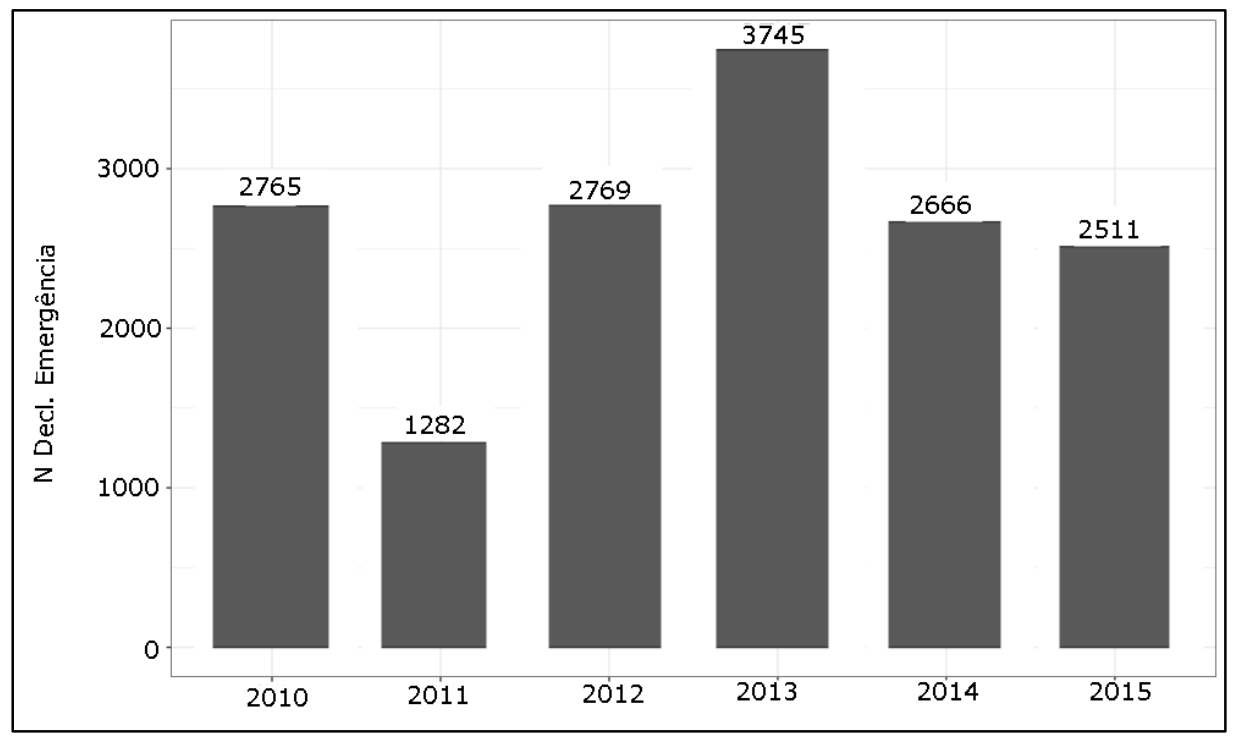

Fonte: Elaboração dos autores com base no Sistema Integrado de Informações sobre Desastres do Ministério do Desenvolvimento Regional14.

Essas declarações são dos mais diversos tipos, sendo as mais frequentes: "estiagem", com 8.448 ocorrências; "seca", com 2.453 ocorrências; e "enxurradas", com 2.181 ocorrências. Devido à natureza dos desastres, seria possível imaginar que essas ocorrências se concentrassem exclusivamente no Nordeste do país. Essa expectativa também tem por base o desenvolvimento econômico relativamente mais baixo dessa região, que poderia estar associado com a maior incidência de declarações de emergência. Para verificar empiricamente o que ocorre, a Figura 2 mostra a distribuição espacial das declarações de emergência no Brasil no período analisado. Na figura, o azul mais claro indica a declaração de emergência, enquanto o azul escuro indica áreas sem declaração de emergência.

14 Disponível em: <https://s2id.mi.gov.br>. Acesso em: dez. 2019. 
Figura 2

Distribuição espacial das declarações de emergência

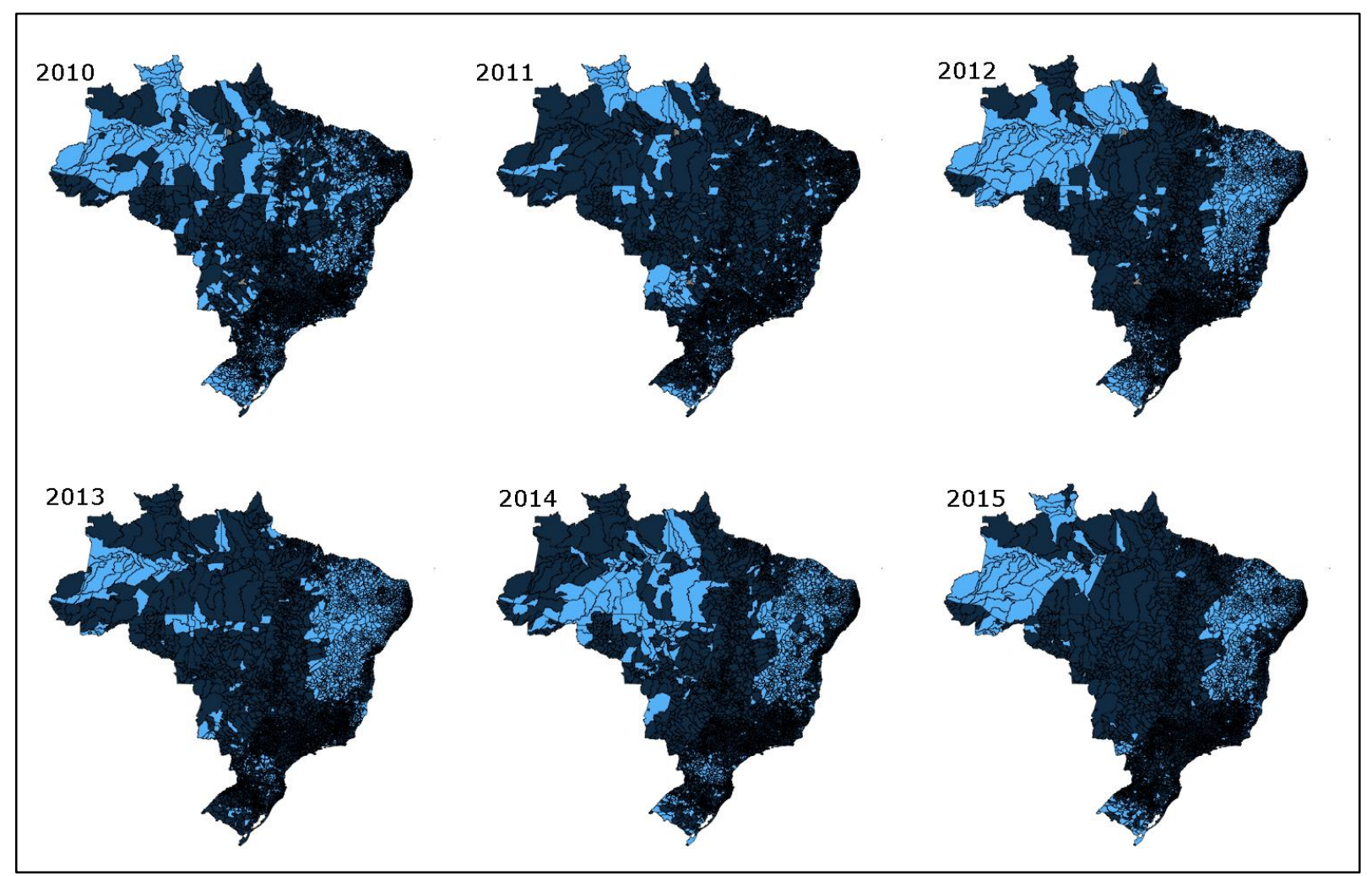

Fonte: Elaboração dos autores com base no Sistema Integrado de Informações sobre Desastres do Ministério do Desenvolvimento Regional.

Observação: O azul mais claro indica a declaração de emergência, enquanto o azul-escuro indica áreas sem declaração de emergência.

Como podemos ver, não há exclusividade da região Nordeste do país em relação às declarações de emergência. Há variação entre os anos, com maior concentração nas regiões Norte e Nordeste de 2012 em diante. Contudo, municípios no extremo sul do país também aparecem com alta incidência de declarações de emergência. Essa distribuição mostra que a decisão do governo federal de reconhecer uma declaração de emergência não é direcionada exclusivamente para uma região ou estado específico do país.

O reconhecimento formal da situação de emergência é um passo importante para os municípios e, apesar de gerar benefícios do ponto de vista dos procedimentos administrativos locais, não gera automaticamente acesso às transferências federais obrigatórias para apoio e reparo dos efeitos do desastre. Podemos ver na Figura 3 a distribuição espacial da alocação das transferências federais de emergência. Na figura, quanto mais claro o tom de azul, maior o valor em transferências federais recebido pelos 
municípios. As áreas em cinza indicam que o município não recebeu transferências no referido ano (valor $\mathrm{R} \$ 0,00$ ).

Figura 3

Distribuição espacial das transferências federais de emergência

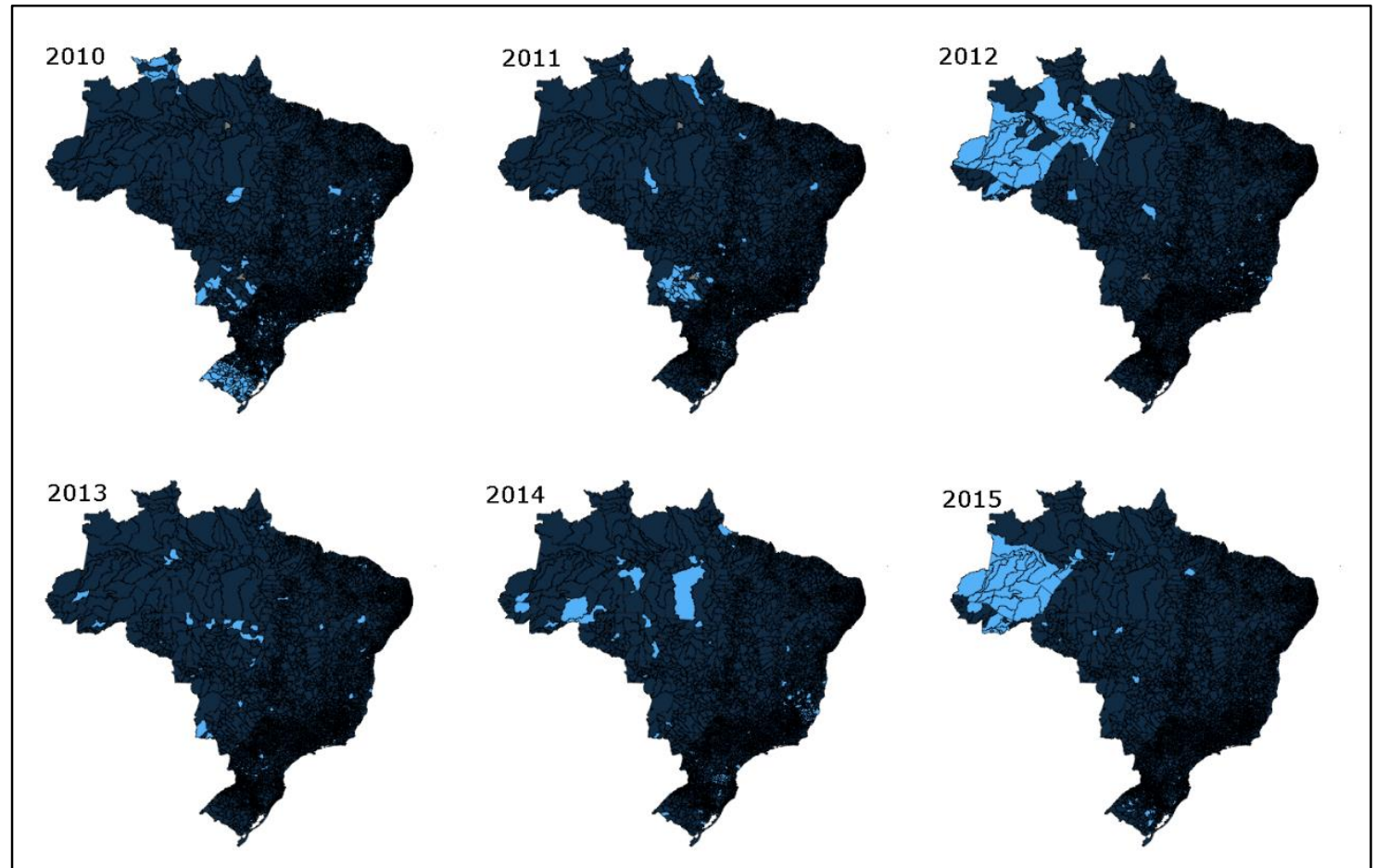

Fonte: Elaboração dos autores com base em dados do Ministério do Desenvolvimento Regional ${ }^{15}$.

Observação: Quanto mais claro o tom de azul, maior o valor em transferências federais recebido pelos municípios.

Podemos ver na Figura 3 que, enquanto a incidência de declarações de emergência reconhecidas pelo governo federal é alta, a distribuição de recursos para o apoio de forma direta aos municípios que sofrem com desastres naturais é muito mais rara. No período analisado ocorreram apenas 1.303 transferências obrigatórias para os municípios para fins de apoio emergencial em situação de desastre. Contudo, mesmo sendo a incidência municipal baixa, os valores não deixam de ser expressivos: em 2010, R\$1.195.859.475; em 2011, R\$ 223.484.254; em 2012, R\$239.007.559; em 2013, R\$270.302.179; em 2014, R\$ 285.695.318; e, por fim, em 2015, R\$ 101.296.418. A Tabela 1 apresenta o percentual de municípios que efetivamente receberam transferências federais de emergência em cada ano e a média do valor per capita transferido. O percentual e as médias são calculados entre os municípios afetados por desastres no referido ano.

15 Disponível em: <https://www.gov.br/mdr/pt-br>. Acesso em: dez. 2020. 
Tabela 1

Alocação de transferências federais para os municípios brasileiros

\begin{tabular}{|l|c|c|}
\hline Ano & Recebedores (\%) & $\begin{array}{c}\text { Valor per capita } \\
\text { (média e desvio-padrão) }\end{array}$ \\
\hline 2010 & 23,3 & $152.06(189.99)$ \\
\hline 2011 & 12,2 & $54.07(103.91)$ \\
\hline 2012 & 4,9 & $69.60(137.02)$ \\
\hline 2013 & 3,0 & $73.64(83.93)$ \\
\hline 2015 & 5,6 & $59.27(160.85)$ \\
\hline
\end{tabular}

Fonte: Elaboração dos autores com base em dados do Ministério do Desenvolvimento Regional.

Os dados da Tabela 1 mostram que uma parcela pequena dos municípios afetados por desastres é de fato beneficiada com transferências federais. Além disso, os valores médios também variam expressivamente entre os diferentes municípios, dado que o desvio-padrão é sempre mais alto que a média no período analisado. Buscamos então entender a variação no reconhecimento federal das situações de emergência e no acesso dos municípios aos recursos de transferências para esse fim. Isto é, quem é beneficiado e quem é prejudicado nessas decisões; quem tem declarações de emergência reconhecidas pelo governo federal; quem recebe recursos de transferências federais; e, mais importante, em que medida a alocação desses recursos obedece a critérios de alinhamento político. A Tabela 2 apresenta os resultados para as declarações de emergência e a Tabela 3, os resultados para as transferências federais: 
Tabela 2

Alinhamento político e reconhecimento da declaração de emergência

\begin{tabular}{|c|c|c|c|c|c|c|}
\hline & \multicolumn{6}{|c|}{ Variável dependente } \\
\hline & \multicolumn{6}{|c|}{$\mathrm{N}$ reconhecimento desastres } \\
\hline & (1) & (2) & (3) & (4) & (5) & (6) \\
\hline $\begin{array}{l}\text { Alinhamento } \\
\text { Presidente }\end{array}$ & $\begin{array}{c}0.013 \\
(0.027) \\
\end{array}$ & & & $\begin{array}{c}0.015 \\
(0.027) \\
\end{array}$ & & \\
\hline $\begin{array}{l}\text { Alinhamento } \\
\text { Coalizão }\end{array}$ & & $\begin{array}{l}0.038^{* *} \\
(0.017)\end{array}$ & & & $\begin{array}{l}0.038^{* *} \\
(0.017)\end{array}$ & \\
\hline $\begin{array}{l}\text { Alinhamento } \\
\text { Ministro }\end{array}$ & & & $\begin{array}{l}0.123^{* * *} \\
(0.028)\end{array}$ & & & $\begin{array}{l}0.059^{* *} \\
(0.028)\end{array}$ \\
\hline $\begin{array}{l}\text { Burocracia } \\
\text { Comissionada }\end{array}$ & $\begin{array}{l}0.003^{* * *} \\
(0.001)\end{array}$ & $\begin{array}{l}0.003^{* * *} \\
(0.001)\end{array}$ & $\begin{array}{l}0.003^{* *} \\
(0.001)\end{array}$ & $\begin{array}{l}0.003^{* * *} \\
(0.001)\end{array}$ & $\begin{array}{l}0.003^{* * *} \\
(0.001)\end{array}$ & $\begin{array}{l}0.003^{* * *} \\
(0.001)\end{array}$ \\
\hline $\begin{array}{l}\text { Cobertura } \\
\text { PBF }\end{array}$ & $\begin{array}{l}0.041^{* * *} \\
(0.002)\end{array}$ & $\begin{array}{l}0.042^{* * *} \\
(0.002)\end{array}$ & $\begin{array}{l}0.041^{* * *} \\
(0.002)\end{array}$ & $\begin{array}{l}0.040^{* * *} \\
(0.002)\end{array}$ & $\begin{array}{l}0.040^{* * *} \\
(0.002)\end{array}$ & $\begin{array}{l}0.040^{* * *} \\
(0.002)\end{array}$ \\
\hline N Desastres & $\begin{array}{l}0.075^{* * *} \\
(0.003)\end{array}$ & $\begin{array}{l}0.076^{* * *} \\
(0.003)\end{array}$ & $\begin{array}{l}0.075^{* * *} \\
(0.003)\end{array}$ & $\begin{array}{l}0.076^{* * *} \\
(0.003)\end{array}$ & $\begin{array}{l}0.076^{* * *} \\
(0.003)\end{array}$ & $\begin{array}{l}0.076^{* * *} \\
(0.003)\end{array}$ \\
\hline Reeleito & $\begin{array}{c}-0.017 \\
(0.018)\end{array}$ & $\begin{array}{c}-0.018 \\
(0.018) \\
\end{array}$ & $\begin{array}{c}-0.019 \\
(0.018) \\
\end{array}$ & $\begin{array}{c}-0.003 \\
(0.018) \\
\end{array}$ & $\begin{array}{c}-0.004 \\
(0.018) \\
\end{array}$ & $\begin{array}{c}-0.003 \\
(0.018) \\
\end{array}$ \\
\hline Ano Eleitoral & $\begin{array}{l}0.056^{* * *} \\
(0.018)\end{array}$ & $\begin{array}{l}0.059^{* * *} \\
(0.018)\end{array}$ & $\begin{array}{l}0.057^{* * *} \\
(0.018)\end{array}$ & $\begin{array}{l}0.256^{* * *} \\
(0.030)\end{array}$ & $\begin{array}{l}0.257^{* * *} \\
(0.030)\end{array}$ & $\begin{array}{l}0.247^{* * *} \\
(0.031)\end{array}$ \\
\hline $\begin{array}{l}\text { Votos } \\
\text { Presidente }\end{array}$ & $\begin{array}{l}0.003^{* * *} \\
(0.001) \\
\end{array}$ & $\begin{array}{l}0.003^{* * *} \\
(0.001) \\
\end{array}$ & $\begin{array}{l}0.003^{* * *} \\
(0.001) \\
\end{array}$ & $\begin{array}{l}0.003^{* * *} \\
(0.001)\end{array}$ & $\begin{array}{l}0.003^{* * *} \\
(0.001)\end{array}$ & $\begin{array}{l}0.003^{* * *} \\
(0.001) \\
\end{array}$ \\
\hline $\begin{array}{l}\text { Estado } \\
\text { Ministro }\end{array}$ & $\begin{array}{l}0.141^{* * *} \\
(0.029)\end{array}$ & $\begin{array}{l}0.141^{* * *} \\
(0.029)\end{array}$ & $\begin{array}{l}0.129^{* * *} \\
(0.030)\end{array}$ & $\begin{array}{l}0.155^{* * *} \\
(0.029)\end{array}$ & $\begin{array}{l}0.154^{* * *} \\
(0.029)\end{array}$ & $\begin{array}{l}0.149^{* * *} \\
(0.030)\end{array}$ \\
\hline $\begin{array}{l}\text { Log } \\
\text { População }\end{array}$ & $\begin{array}{c}-0.052^{* * *} \\
(0.008)\end{array}$ & $\begin{array}{c}-0.051^{* * *} \\
(0.008)\end{array}$ & $\begin{array}{c}-0.051^{* * *} \\
(0.008)\end{array}$ & $\begin{array}{c}-0.058^{* * *} \\
(0.008)\end{array}$ & $\begin{array}{c}-0.057^{* * *} \\
(0.008)\end{array}$ & $\begin{array}{c}-0.057^{* * *} \\
(0.008)\end{array}$ \\
\hline $\begin{array}{l}\text { Efeitos Fixos } \\
\text { (Ano) }\end{array}$ & NÃO & NÃO & NÃO & SIM & SIM & SIM \\
\hline Constante & $\begin{array}{c}-0.239^{* * *} \\
(0.090)\end{array}$ & $\begin{array}{c}-0.273^{* * *} \\
(0.091)\end{array}$ & $\begin{array}{c}-0.253^{* * *} \\
(0.090)\end{array}$ & $\begin{array}{c}-0.247^{* * *} \\
(0.092)\end{array}$ & $\begin{array}{c}-0.282^{* * *} \\
(0.094)\end{array}$ & $\begin{array}{c}-0.254^{* * *} \\
(0.092)\end{array}$ \\
\hline Observações & 12567 & 12567 & 12567 & 12567 & 12567 & 12567 \\
\hline $\begin{array}{l}\text { Log } \\
\text { Likelihood }\end{array}$ & $-15,467.930$ & $-15,465.680$ & $-15,458.520$ & $-15,318.050$ & $-15,315.810$ & $-15,316.060$ \\
\hline $\begin{array}{l}\text { Akaike Inf. } \\
\text { Crit. }\end{array}$ & $30,955.860$ & $30,951.350$ & $30,937.030$ & $30,664.110$ & $30,659.620$ & $30,660.110$ \\
\hline
\end{tabular}

Fonte: Elaboração dos autores com base em dados do IBGE, Ministério do Desenvolvimento Regional, Ministério do Desenvolvimento Social e Tribunal Superior Eleitoral.

Nota: $* * p<0.05 ; * * * p<0.01$. Coeficientes reportados. Erro-padrão entre parênteses.

Os modelos na Tabela 2 apresentam a relação entre as variáveis de interesse e o número de declarações reconhecidas pelo governo federal. Como o reconhecimento formal traz benefícios para os municípios, esperamos que os municípios alinhados ao governo federal tenham maior chance de ser beneficiados. As variáveis de interesse são as três primeiras, que apresentam as medidas de alinhamento partidário entre o prefeito e o governo federal. Como podemos ver, das três especificações da variável de alinhamento, o alinhamento com a coalizão e o alinhamento com o ministro do MI apresentam o sinal positivo e são estatisticamente significantes. $\mathrm{O}$ alinhamento com o presidente apresenta o 
sinal positivo esperado, mas não alcança significância estatística nas duas especificações consideradas.

Para a interpretação substancial dos coeficientes, é preciso converter os valores para a escala original, que é a contagem de declarações de emergência reconhecidas pelo governo federal. Esse procedimento é realizado, mantendo as demais variáveis dos modelos na média. A análise do efeito substancial mostra que o incremento no número de declarações reconhecidas é pequeno. No caso do alinhamento entre o presidente e o partido do prefeito, o incremento é de 0,1 declarações reconhecidas, e esse incremento não é estatisticamente significante, como já informado. Para o alinhamento com a coalizão, o incremento é de 0,4 declarações, com municípios não alinhados apresentando 1,07 declarações reconhecidas e municípios alinhados, 1,11 declarações. Por último, o alinhamento com o ministro apresenta um incremento de 0,15 declarações reconhecidas, com os municípios não alinhados ao partido do ministro apresentando 1,08 declarações reconhecidas e os municípios alinhados, 1,32 declarações.

As variáveis de controle são divididas em dois grupos: as variáveis de capacidade/necessidade e as variáveis eleitorais. Primeiro, com relação à variável de burocracia, ao contrário do esperado, a proporção da burocracia municipal que é somente comissionada está associada positivamente com o número de declarações de emergência. Esse resultado indica que as conexões políticas dos nomeados acabam por ajudar o reconhecimento federal. Já as variáveis de necessidade, tanto a cobertura do PBF quanto o número de desastres reportado, apresentam o sinal positivo esperado e são estatisticamente significantes.

Os resultados mostram que essas são as variáveis que apresentam maior incremento no número de declarações. Municípios com cobertura do PBF de $10 \%$ da população apresentam 1,04 declarações de emergência reconhecidas. Esse número aumenta para 1,58 com cobertura de $20 \%$ e 2,42 com cobertura de $30 \%$, valor máximo. Já com relação ao número de desastres reportados pelo município, era de esperar que, quanto mais desastres, maior o número de declarações reconhecidas. Os resultados mostram que municípios que reportaram um desastre apresentam 1,06 declarações de emergência reconhecidas. Esse número aumenta para 1,44 com cinco desastres reportados e para 2,12 com dez desastres reportados. Esse resultado mostra que o número de desastres sofridos pelo município importa, mas a relação entre número de desastres e número de declarações de emergência reconhecidas pelo governo federal está longe de ser perfeita.

Esses resultados mostram que o número-base de declarações reconhecidas é de uma declaração por município e que, apesar de a política importar, uma vez que o alinhamento com a coalizão e, especialmente, com o ministro apresenta incremento no número de declarações, esse incremento é razoavelmente pequeno. Em suma, as variáveis de alinhamento político têm incremento apenas discreto e as variáveis de necessidade e 
vulnerabilidade têm de assumir os seus valores máximos para ter como retorno uma declaração a mais de emergência reconhecida pelo governo federal.

Com relação às variáveis eleitorais, o prefeito em segundo mandato não apresenta diferença significante. Ano eleitoral está associado com maior número de declarações de emergência reconhecidas. Os resultados mostram também que o presidente busca beneficiar seu eleitorado, já que, quanto maior o percentual de votos para o presidente no município, maior o número de declarações reconhecidas. Essa relação também é observada para o ministro, que beneficia o seu distrito eleitoral com o maior reconhecimento de declarações de emergência no seu estado de origem.

A Tabela 3 apresenta os resultados para a alocação de transferências federais. Podemos ver, então, se os fatores que explicam o reconhecimento federal da situação de emergência são os mesmos que explicam o recebimento de transferências emergenciais e a magnitude dos valores. 
Tabela 3

Alinhamento político e transferências federais de emergência

\begin{tabular}{|c|c|c|c|c|c|c|}
\hline & \multicolumn{6}{|c|}{ Variável dependente } \\
\hline & \multicolumn{3}{|c|}{ Transferências - Binária } & \multicolumn{3}{|c|}{ Transferência per capita } \\
\hline & \multicolumn{3}{|c|}{ Logit } & \multicolumn{3}{|c|}{ Log-normal } \\
\hline & (1) & (2) & (3) & (4) & (5) & (6) \\
\hline $\begin{array}{l}\text { Alinhamento } \\
\text { Presidente }\end{array}$ & $\begin{array}{c}0.002 \\
(0.107)\end{array}$ & & & $\begin{array}{c}-0.273 * * \\
(0.125)\end{array}$ & & \\
\hline $\begin{array}{l}\text { Alinhamento } \\
\text { Coalizão }\end{array}$ & & $\begin{array}{c}0.472 * * * \\
(0.081)\end{array}$ & & & $\begin{array}{c}0.009 \\
(0.097)\end{array}$ & \\
\hline $\begin{array}{l}\text { Alinhamento } \\
\text { Ministro }\end{array}$ & & & $\begin{array}{c}0.635 * * * \\
(0.105)\end{array}$ & & & $\begin{array}{c}0.441 * * * \\
(0.119)\end{array}$ \\
\hline $\begin{array}{l}\text { Burocracia } \\
\text { Comissionada }\end{array}$ & $\begin{array}{l}-0.002 \\
(0.005)\end{array}$ & $\begin{array}{l}-0.003 \\
(0.005)\end{array}$ & $\begin{array}{l}-0.003 \\
(0.005)\end{array}$ & $\begin{array}{c}0.030 * * * \\
(0.006)\end{array}$ & $\begin{array}{c}0.031 * * * \\
(0.006)\end{array}$ & $\begin{array}{c}0.028^{* * *} \\
(0.006)\end{array}$ \\
\hline Cobertura PBF & $\begin{array}{c}-0.110 * * * \\
(0.009) \\
\end{array}$ & $\begin{array}{c}-0.103 * * * \\
(0.009)\end{array}$ & $\begin{array}{c}-0.109 * * * \\
(0.009)\end{array}$ & $\begin{array}{c}0.060 * * * \\
(0.013)\end{array}$ & $\begin{array}{c}0.062 * * * \\
(0.013)\end{array}$ & $\begin{array}{c}0.062 * * * \\
(0.013)\end{array}$ \\
\hline N Desastres & $\begin{array}{c}0.076 * * * \\
(0.029)\end{array}$ & $\begin{array}{c}0.078^{* * *} \\
(0.029)\end{array}$ & $\begin{array}{c}0.077 * * * \\
(0.029)\end{array}$ & $\begin{array}{c}-0.167 * * * \\
(0.050)\end{array}$ & $\begin{array}{c}-0.177 * * * \\
(0.050)\end{array}$ & $\begin{array}{c}-0.177 * * * \\
(0.050)\end{array}$ \\
\hline Reeleito & $\begin{array}{l}-0.044 \\
(0.076)\end{array}$ & $\begin{array}{l}-0.063 \\
(0.076)\end{array}$ & $\begin{array}{l}-0.063 \\
(0.076)\end{array}$ & $\begin{array}{c}-0.207 * * \\
(0.087)\end{array}$ & $\begin{array}{c}-0.205^{* *} \\
(0.087)\end{array}$ & $\begin{array}{c}-0.212 * * \\
(0.087)\end{array}$ \\
\hline Ano Eleitoral & $\begin{array}{c}1.111 * * * \\
(0.072)\end{array}$ & $\begin{array}{c}1.147 * * * \\
(0.072)\end{array}$ & $\begin{array}{c}1.085 * * * \\
(0.072)\end{array}$ & $\begin{array}{c}0.704 * * * \\
(0.089)\end{array}$ & $\begin{array}{c}0.698 * * * \\
(0.089)\end{array}$ & $\begin{array}{c}0.650 * * * \\
(0.089)\end{array}$ \\
\hline Votos Presidente & $\begin{array}{c}-0.019 * * * \\
(0.003)\end{array}$ & $\begin{array}{c}-0.020 * * * \\
(0.003)\end{array}$ & $\begin{array}{c}-0.019 * * * \\
(0.003)\end{array}$ & $\begin{array}{c}-0.018 * * * \\
(0.003)\end{array}$ & $\begin{array}{c}-0.019 * * * \\
(0.003)\end{array}$ & $\begin{array}{c}-0.018 * * * \\
(0.003)\end{array}$ \\
\hline Estado Ministro & $\begin{array}{c}0.557 * * * \\
(0.155)\end{array}$ & $\begin{array}{c}0.521^{* * *} \\
(0.156)\end{array}$ & $\begin{array}{c}0.487 * * * \\
(0.156)\end{array}$ & $\begin{array}{c}0.082 \\
(0.206)\end{array}$ & $\begin{array}{c}0.097 \\
(0.207)\end{array}$ & $\begin{array}{l}-0.078 \\
(0.210)\end{array}$ \\
\hline Constante & $\begin{array}{c}-0.984 * * * \\
(0.165) \\
\end{array}$ & $\begin{array}{c}-1.303 * * * \\
(0.175) \\
\end{array}$ & $\begin{array}{c}-1.057 * * * \\
(0.165) \\
\end{array}$ & $\begin{array}{c}4.030 * * * \\
(0.221) \\
\end{array}$ & $\begin{array}{c}3.999 * * * \\
(0.233)\end{array}$ & $\begin{array}{c}3.928^{* * *} \\
(0.221) \\
\end{array}$ \\
\hline Observações & 12567 & 12567 & 12567 & 12567 & 12567 & 12567 \\
\hline Grupos & 4118 & 4118 & 4118 & 4118 & 4118 & 4118 \\
\hline Correlação E.A. & 0.124 & 0.135 & 0.123 & 0.124 & 0.135 & 0.123 \\
\hline Log Likelihood & -4722.11 & -4706.59 & -4700.58 & -4722.11 & -4706.59 & -4700.58 \\
\hline Akaike Inf. Crit. & 9488.23 & 9457.18 & 9445.17 & 9488.23 & 9457.18 & 9445.17 \\
\hline $\begin{array}{l}\text { Log Residual Std. } \\
\text { Dev. }\end{array}$ & 0.117 & 0.122 & 0.111 & 0.117 & 0.122 & 0.111 \\
\hline
\end{tabular}

Fonte: Elaboração dos autores com base em dados do IBGE, Ministério do Desenvolvimento Regional, Ministério do Desenvolvimento Social e Tribunal Superior Eleitoral.

Nota: ${ }^{* *} \mathrm{p}<0.05 ; * * * \mathrm{p}<0.01$. Coeficientes reportados. Erro-padrão entre parênteses.

Como explicado na seção "Metodologia", o modelo para analisar a relação entre o alinhamento partidário e a alocação de transferências federais é estimado em duas partes. Os modelos de 1 a 3 têm como resposta o recebimento ou não de transferências federais pelo município no ano. Os modelos de 4 a 6 têm como resposta o valor per capita recebido pelo município, condicional ao recebimento de transferência no ano. Ressaltamos que, 
nesse modelo de mixture, são estimados interceptos para cada município e é permitido que esses interceptos sejam correlacionados entre o modelo da primeira parte e o da segunda parte. O número de grupos (municípios) analisados e essa correlação são apresentados no final da Tabela 3. Na prática, isso significa que os modelos são dependentes. Nos "Anexos", apresentamos os modelos estimados de forma independente. Nota-se que os resultados são os mesmos.

Começando com os modelos que estimam a relação entre o alinhamento e o recebimento ou não de transferências, notamos que as três especificações de alinhamento partidário apresentam sinal positivo. Contudo, o alinhamento com o presidente não apresenta significância estatística. O resultado indica que municípios com prefeitos de partidos da coalizão de governo ou, especificamente, do mesmo partido do ministro do Integração Nacional apresentam maior probabilidade de receber transferências federais de emergência. Substantivamente, o município com prefeito alinhado à coalizão apresenta incremento de 0,021 na probabilidade de receber transferências. Já o alinhamento com o partido do ministro apresenta incremento de 0,037. 0 incremento na probabilidade pode ser considerado pequeno. Contudo, a probabilidade de receber transferências é em geral muito baixa. Isso ocorre porque o recebimento de transferências de emergência, mesmo considerando que todos os municípios na análise foram afetados por desastres, é relativamente raro ${ }^{16}$. Dessa forma, um incremento de $2,1 \%$ e $3,7 \%$ para o alinhamento com a coalizão e o ministro, respectivamente, não é desprezível.

Considerando as variáveis de controle, das variáveis de capacidade/necessidade, a burocracia não apresenta resultado significante. A cobertura do PBF apresenta significância, mas com o sinal negativo. Isso indica que, quanto maior a vulnerabilidade do município, menor a probabilidade de receber transferências de emergência. Esse resultado pode parecer contraintuitivo quando partimos do pressuposto de que os municípios que precisam mais deveriam ser mais beneficiados. Contudo, um dos poucos trabalhos que fazem referência a esse ponto explicitamente mostra que a necessidade não determina quem será beneficiado (Baião, Couto e Oliveira, 2019). O número de desastres reportado pelo município afeta positivamente a probabilidade de recebimento de transferências. Esse resultado sim indica uma ligação entre a demanda ou necessidade de recursos e a alocação das transferências.

Por último, as variáveis eleitorais indicam que o fato de o prefeito estar no segundo mandato não afeta o recebimento de transferências, mas que ano eleitoral apresenta maior probabilidade de recebimento de transferências federais pelos municípios. O percentual de votos do presidente tem relação negativa com o recebimento de transferências. Contudo, o estado do ministro é mais beneficiado. Isso indica a sobreposição do ministro sobre o presidente na busca por beneficiar o seu distrito eleitoral.

16 Como visto na Tabela 1, menos de $10 \%$ dos municípios afetados por desastres são beneficiados por transferências federais. 
Esses resultados podem ser interessantes, mas o foco da análise está de fato nos modelos que estimam o valor alocado aos municípios. Nesse caso, os resultados mostram que, condicional ao município receber transferências federais, o valor tende a ser menor quando o prefeito é alinhado ao presidente e tende a ser maior quando o prefeito é alinhado ao ministro. Além disso, esse efeito é substancial. Municípios alinhados ao partido do presidente, quando recebem recursos, recebem $23 \%$ menos do que os municípios não alinhados. Já no caso dos municípios alinhados ao partido do ministro, quando recebem transferências federais, recebem 55\% a mais no valor per capita. Considerando o valorbase de $\mathrm{R} \$ 76,00$ per capita, um município com prefeito alinhado ao partido do ministro receberá em média $\mathrm{R} \$ 41,8$ a mais para cada habitante. Importante notar que, no caso do valor transferido, somente o ministro apresenta capacidade de direcionar recursos para prefeitos do seu partido, demonstrando a posição privilegiada desse ator no processo decisório acerca da política distributiva.

Considerando as variáveis de controle, burocracia comissionada, assim como nos modelos sobre o reconhecimento federal, também apresenta relação positiva, indicando que, quanto maior a proporção de comissionados, maior o valor per capita recebido em transferências federais de emergência. A cobertura do PBF aumenta o valor alocado para os municípios, de forma que, quanto maior a cobertura, maior o valor per capita recebido. Esse resultado indica que municípios mais vulneráveis têm menor chance de receber recursos. Mas, quando recebem recursos, o valor tende a ser maior de acordo com o grau de vulnerabilidade. A última medida de necessidade, o número de desastres reportados, apresenta o sinal negativo. Isso indica que maior demanda não necessariamente se traduz de forma direta em maior assistência por meio de maior volume de transferências.

Sobre as variáveis eleitorais, prefeitos em segundo mandato recebem menos recursos que os prefeitos em primeiro mandato. Condicional a receber algum recurso, os municípios recebem mais transferências em anos eleitorais. Por último, quando os municípios recebem recursos, o valor transferido tende a ser menor quanto maior o apoio eleitoral do presidente. $O$ estado do ministro não apresenta efeito significante sobre o valor em transferências alocado.

Podemos agora comparar os efeitos observados das nossas variáveis de interesse sobre o número de declarações de emergência, o recebimento ou não de transferências e o volume de transferências recebido. De início já notamos que o efeito das variáveis de alinhamento muda com relação aos modelos anteriores. Considerando o valor alocado, somente o alinhamento com o ministro apresenta o resultado positivo e estatisticamente significante esperado. Isso quer dizer que, enquanto o alinhamento com a coalizão e com o ministro é relevante para o reconhecimento federal da declaração de emergência e para o recebimento de transferências, somente o alinhamento com o ministro tem efeito positivo e estatisticamente significante sobre o valor recebido. Dessa forma, o ministro mostra maior capacidade de direcionar quanto será alocado para os municípios e, assim, beneficiar os municípios aliados. 
Em suma, nossos resultados mostram que a política importa. Municípios alinhados ao governo federal são mais beneficiados na alocação de recursos relacionados a desastres naturais. Municípios alinhados à coalizão e ao ministro do MI são beneficiados na decisão sobre o reconhecimento formal da declaração de emergência e também na decisão de alocar recursos de transferências federais. Contudo, no que diz respeito ao valor transferido, o ministro prioriza os municípios alinhados ao seu próprio partido político. A análise aqui desenvolvida contribui ainda para a literatura sobre política distributiva, mostrando que, mesmo em situações de definição exógena da demanda, o alinhamento partidário ainda é fundamental para explicar quem ganha o quê.

\section{Conclusão}

Neste artigo, analisamos a politização das decisões federais quanto aos recursos relacionados à emergência nos municípios brasileiros. Desastres naturais são situações causadas por razões exógenas, fora do controle dos gestores públicos. Contudo, como os gestores reagem a essas situações é algo a ser compreendido sob a luz dos incentivos políticos e eleitorais para os representantes eleitos. Quando os municípios se deparam com uma situação de emergência, a estrutura federativa do Brasil prevê que eles podem recorrer ao governo federal para conseguir apoio.

Esse apoio pode vir na forma do reconhecimento formal da declaração de emergência, reconhecimento esse que gera flexibilidade jurídica para os municípios organizarem a reação ao desastre natural. O apoio federal pode vir também na forma de transferências federais de emergência. Esse é um apoio mais direto na forma de recursos financeiros para ajudar na prevenção e na recuperação de áreas afetadas por desastres. A questão que se colocou então foi se essas formas de apoio são alocadas de forma neutra ou são direcionadas para prefeitos alinhados politicamente.

Analisando dados originais sobre as declarações de emergência e sobre a alocação de transferências federais para esse fim, mostramos que, enquanto o reconhecimento formal da emergência é relativamente frequente, a alocação de transferências é mais limitada. Contudo, em ambas as situações, é preciso uma decisão discricionária do governo federal quanto a quem será priorizado. Considerando as especificidades do presidencialismo de coalizão brasileiro, testamos o efeito do alinhamento do prefeito com o presidente, com a coalizão e com o ministro da Integração Nacional.

Os resultados mostram que o alinhamento partidário apresenta efeito positivo sobre a alocação de recursos de emergência. No caso do reconhecimento formal da declaração de emergência e do recebimento de transferências federais, o alinhamento com a coalizão e com o ministro afeta positivamente as chances dos municípios. O alinhamento partidário com esses atores se traduz em incremento no número de declarações de emergência reconhecidas pelo governo federal. Essa capacidade de beneficiar os prefeitos alinhados com a coalizão e com o ministro do MI se mantém quando consideramos a 
diferenciação entre os municípios que recebem transferências e aqueles que não recebem. Municípios alinhados com a coalizão e com o partido do ministro apresentam maior probabilidade de receber recursos de transferências federais. Contudo, quando consideramos o valor em transferências federais de emergência, somente o alinhamento com o ministro apresenta o efeito positivo e estatisticamente significante esperado.

Esses resultados mostram que a política é relevante para compreendermos a alocação de recursos, que, num primeiro momento, poderíamos pensar ser completamente determinada pela demanda ou necessidade desses recursos. Os atores políticos do Poder Executivo - presidente, coalizão e ministro - têm incentivos políticos para buscar beneficiar os seus aliados. Com poder discricionário para alocar recursos, esses atores influenciam o reconhecimento de declarações de emergência, a alocação de recursos de transferências federais e o valor dos recursos a serem alocados. Mostramos que, nessa briga por influência, o ministro da Integração Nacional apresenta papel proeminente, sendo capaz de extrair benefícios para os seus aliados em todas as três decisões sobre situações de emergência. Esse resultado não quer dizer que fatores contextuais de vulnerabilidade e demanda por recursos não importam. Vimos que esses fatores importam e, em algumas situações, em magnitude maior que o alinhamento político. Contudo, mantendo esses fatores constantes, mostramos aqui que os atores políticos direcionam recursos e beneficiam aliados.

Dessa forma, as principais contribuições do presente artigo são: primeiro, exploramos a complexidade do processo decisório do Executivo, identificando não somente o efeito do alinhamento partidário do prefeito com o governo, mas especificamos a qual ator do Executivo Federal o prefeito é alinhado e qual o efeito dos diferentes alinhamentos sobre o acesso aos recursos do governo federal. Esse resultado mostra que presidente, coalizão e ministro são relevantes para a política distributiva, mas, no caso das transferências de emergência, o papel do ministro é central. Segundo, mostramos que, mesmo se tratando de situações de emergência, o elemento político é fundamental para explicar quem será beneficiado e quem será prejudicado. Os atores políticos utilizam os recursos a sua disposição para beneficiar os prefeitos alinhados, mesmo em situações de desastre natural.

\section{Referências bibliográficas}

ABRANCHES, S. "Presidencialismo de coalizão: o dilema institucional brasileiro". Dados, vol. 31, no 1, p. 1-39, 1988.

AMES, B. The deadlock of democracy in Brazil. Michigan: University of Michigan Press, 2001.

Amorim Neto, O. "The presidential calculus: executive policy making and cabinet formation in the Americas". Comparative Political Studies, vol. 39, no 4, p. 415-440, 2006.

Amorim Neto, O.; Simonassi, A. G. "Bases políticas das transferências intergovernamentais no Brasil (1985-2004)". Revista de Economia Política, vol. 33, no 4, p. 704-725, 2013. 
Andersson, W. A.; Kennedy, P. A.; Ressler, E. Handbook of disaster research. New York: Springer, 2007.

ARRetChe, M.; Rodden, J. "Política distributiva na Federação: estratégias eleitorais, barganhas legislativas e coalizões de governo". Dados, Rio de Janeiro, vol. 47, no 3, p. 549-576, 2004.

BAIÃo, A. L.; Couto, C.; JucÁ, I. C. "A execução das emendas orçamentárias individuais: papel de ministros, cargos de liderança e normas fiscais". Revista Brasileira de Ciência Política, no 25, p. 4786, 2018.

BaiÃo, A. L.; Couto, C.; Oliveira, V. E. "Quem ganha o quê, quando e como? Emendas orçamentárias em saúde no Brasil". Revista de Sociologia e Política, vol. 27, no 71, 2019.

BAstos, P.; MilleR, S. "Politics under the weather: droughts, parties and electoral outcomes". InterAmerican Development Bank, 2013.

BATISTA, M. "O mistério dos ministérios: a governança da coalizão no presidencialismo brasileiro". Tese de Doutorado em Ciência Política. Universidade Federal de Pernambuco, Recife, 2014.

. "Burocracia local e qualidade da implementação de políticas descentralizadas: uma análise da gestão de recursos federais pelos municípios brasileiros". Revista do Serviço Público, vol. 66 , no 3, p. 345-370, 2 set. 2015.

. "Who gets what and how does it matter? Importance-weighted portfolio allocation and coalition support in Brazil". Journal of Politics in Latin America, vol. 10, no 3, p. 99-134, 2018.

Berry, C. R.; Burden, B. C.; Howell, W. G. "The president and the distribution of federal spending". American Political Science Review, vol. 104, n 4, p. 783-799, 2010.

Bertholini, F.; Pereira, C.; Rennó, L. "Pork is policy: dissipative inclusion at the local level". Governance, vol. 31, no 4, p. 701-720, 2018.

BOHLKEN, A. T. "Targeting ordinary voters or political elites? Why pork is distributed along partisan lines in India". American Journal of Political Science, vol. 62, no 4, p. 796-812, 2018.

Borges, A. "Eleições presidenciais, federalismo e política social". Revista Brasileira de Ciências Sociais, vol. 28, no 81, p. 117-136, 2013.

BRASIL. Decreto no 7.257, de 4 de agosto de 2010. Regulamenta a Medida Provisória no 494 de 2 de julho de 2010. Presidência da República - Casa Civil. Disponível em:

<http://www.planalto.gov.br/ccivil_03/_Ato2007-2010/2010/Decreto/D7257.htm>. Acesso em: 21 ago. 2010.

. Transferência obrigatória: caderno de orientações. Da solicitação de recursos à prestação de contas. Ministério da Integração Nacional, 2011.

Boletim epidemiológico, desastres naturais e saúde: análise do cenário de eventos hidrológicos no Brasil e seus potenciais impactos sobre o Sistema Único de Saúde. Ministério da Saúde, 2018.

BRollo, F.; NANNiCini, T. "Tying your enemy's hands in close races: the politics of federal transfers in Brazil". American Political Science Review, vol. 106, no 4, p. 742-761, 2012.

BUENO, N. S. "Bypassing the enemy: distributive politics, credit claiming, and non-state organizations in Brazil". Comparative Political Studies, vol. 51, no 3, p. 304-340, 2018.

CAVAlCANTI, F. "Voters sometimes provide the wrong incentives. The lesson of the Brazilian drought industry". Munich Personal RePec Archive, 7 mar. 2018. 
CHEN, J. "Voter partisanship and the effect of distributive spending on political participation". American Journal of Political Science, vol. 57, no 1, p. 200-217, 2013.

Cox, G. W.; McCuBBins, M. D. "Electoral politics as a redistributive game". The Journal of Politics, vol. 48, no 2, p. 370-389, 1986.

Setting the agenda: responsible party government in the US House of Representatives.

Cambridge: Cambridge University Press, 2005. Press, 2007.

Legislative leviathan: party government in the House. Cambridge: Cambridge University

Swing voters, core voters and distributive politics. In: SHAPIRO, I., et al. (eds.). Political representation. Cambridge, UK: Cambridge University Press, 2010.

DANIELS, R. S. "The rise of politics and the decline of vulnerability as criteria in disaster decisions of the United States, 1953-2009". Disasters, vol. 37, no 4, p. 669-694, 2013.

DEDA, C. C.; KAUCHAKJE, S. "Determinants of fiscal transfers to municipal units: effects of malapportionment of Brazilian electoral districts". Revista de Administração Pública, vol. 53, no 1, p. 150-172, 2019.

DixIT, A.; LONDREGAN, J. "The determinants of success of special interests in redistributive politics". The Journal of Politics, vol. 58, no 4, p. 1.132-1.155, 1996.

Downton, M. W.; PIELKE JR., R. A. "Discretion without accountability: politics, flood damage, and climate". Natural Hazards Review, vol. 2, no 4, p. 157-166, 2001.

FEnNo, R. F. Home style: House members in their districts. Harper Collins, 1978.

Figueiredo, A. C.; Limongi, F. Executivo e Legislativo na nova ordem política. Rio de Janeiro: FGV, 2001.

Gallego, J. "Natural disasters and clientelism: the case of floods and landslides in Colombia". Electoral Studies, vol. 55, p. 73-88, 2018.

GARRETT, T. A.; SObeL, R. S. "The political economy of FEMA disaster payments". Economic inquiry, vol. 41, no 3, p. 496-509, 2003.

GASPER, J. T.; ReEVES, A. "Make it rain? Retrospection and the attentive electorate in the context of natural disasters". American Journal of Political Science, vol. 55, no 2, p. 340-355, 2011.

Golden, M.; Min, B. "Distributive politics around the world". Annual Review of Political Science, vol. $16,2013$.

Healy, A.; Malmotra, N. "Myopic voters and natural disaster policy". American Political Science Review, vol. 103, no 3, p. 387-406, 2009.

IBGE. Pesquisa de informações básicas municipais: perfil dos municípios brasileiros 2013. Instituto Brasileiro de Geografia e Estatística, 2014.

KING, G. "Replication, replication". PS: Political Science \& Politics, vol. 28, no 3, p. 444-452, 1995.

KRAMON, E.; POSNER, D. N. "Who benefits from distributive politics? How the outcome one studies affects the answer one gets". Perspectives on Politics, vol. 11, no 2, p. 461-474, 2013.

KRINeR, D. L.; ReEVeS, A. The particularistic president. Cambridge: Cambridge Books, 2015. 
KUMAR, N. "The political economy of intergovernmental transfers - Evidence from Indian disaster relief". Journal of South Asian Development, vol. 11, no 3, p. 261-275, 2016.

LASWELL, H. Politics: who gets what, when and how. United Kingdom: Pickle Partners Publishing, 1936.

Limongi, F.; Figueiredo, A. "Incentivos eleitorais, partidos e política orçamentária". Dados, vol. 45, no 2, p. 303-344, 2002.

"Processo orçamentário e comportamento legislativo: emendas individuais, apoio ao Executivo e programas de governo". Dados, vol. 48, no 4, p. 737-776, 2005.

LITSCHIG, S. "Are rules-based government programs shielded from special-interest politics? Evidence from revenue-sharing transfers in Brazil". Journal of Public Economics, vol. 96, no 11-12, p. 1.047$1.060,2012$.

Lowi, T. J. "American business, public policy, case-studies, and political theory". World Politics, vol. 16 , no 4, p. 677-715, 1964.

MARENCO, A. "Burocracias profissionais ampliam capacidade estatal para implementar políticas? Governos, burocratas e legislação em municípios brasileiros". Dados, vol. 60, no 4, p. 1.025-1.058, 2017.

Marenco, A.; Strohschoen, M. T. B.; Joner, W. "Capacidade estatal, burocracia e tributação nos municípios brasileiros". Revista de Sociologia e Política, vol. 25, n 64, p. 3-21, 2017.

Meireles, F. "A política distributiva da coalizão". Tese de Doutorado em Ciência Política. Universidade Federal de Minas Gerais, Belo Horizonte, 2019.

Pereira, C.; Mueller, B. "Comportamento estratégico em presidencialismo de coalizão: as relações entre Executivo e Legislativo na elaboração do orçamento brasileiro". Dados, vol. 45, no 2, p. 265301, 2002.

"Partidos fracos na arena eleitoral e partidos fortes na arena legislativa: a conexão eleitoral no Brasil". Dados, vol. 46, no 4, p. 735-771, 2003.

RAile, E. D.; Pereira, C.; Power, T. J. "The executive toolbox: building legislative support in a multiparty presidential regime". Political Research Quarterly, vol. 64, no 2, p. 323-334, 2011.

ReEVES, A. "Political disaster: unilateral powers, electoral incentives, and presidential disaster declarations". The Journal of Politics, vol. 73, no 4, p. 1.142-1.151, 2011.

ReinhardT, G. Y.; Ross, A. D. "Expanding social science through disaster studies". Social Science Quarterly, vol. 100, no 7, p. 2.523-2.529, 2019.

Rich, M. J. "Distributive politics and the allocation of federal grants". American Political Science Review, vol. 83, no 1, p. 193-213, 1989.

SANTOS, F. N. "A two-part bayesian model with elicited priors to analyze longitudinal government expenditures in Latin America". Master of Science in Statistics, Dissertação de Mestrado. UCLA. Los Angeles, California, EUA, 2013.

Shepsle, K. A.; Weingast, B. R. Positive theories of congressional institutions. Michigan: University of Michigan Press, 1995.

STEHR, S. D. "The political economy of urban disaster assistance". Urban Affairs Review, vol. 41, no 4, p. 492-500, 2006. 
SYLVES, R; BúZÁs, Z. I. "Presidential disaster declaration decisions, 1953-2003: what influences odds of approval?". State and Local Government Review, vol. 39, no 1, p. 3-15, 2007.

VASSelAi, F.; MignozZetTI, U. G. "O efeito das emendas ao orçamento no comportamento parlamentar e a dimensão temporal: velhas teses, novos testes". Dados, vol. 57, no 3, p. 817-853, 2014.

\section{Anexos}

Tabela A1

Estatísticas descritivas

\begin{tabular}{|c|c|c|c|c|c|c|c|}
\hline & $\mathbf{N}$ & Média & $\begin{array}{l}\text { Desvio- } \\
\text { padrão }\end{array}$ & Mín. & Pctl(25) & Pctl(75) & Máx. \\
\hline $\begin{array}{l}\text { Burocracia } \\
\text { Comissionada }\end{array}$ & 12574 & 10.358 & 7.317 & 0.000 & 5.361 & 13.277 & 79.167 \\
\hline $\begin{array}{l}\text { Alinhamento } \\
\text { Coalizão }\end{array}$ & 12609 & 0.623 & 0.485 & 0.000 & 0.000 & 1.000 & 1.000 \\
\hline Alinhamento Ministro & 12609 & 0.089 & 0.285 & 0.000 & 0.000 & 0.000 & 1.000 \\
\hline $\begin{array}{l}\text { Alinhamento } \\
\text { Presidente }\end{array}$ & 12609 & 0.119 & 0.323 & 0.000 & 0.000 & 0.000 & 1.000 \\
\hline Estado Ministro & 12606 & 0.071 & 0.257 & 0.000 & 0.000 & 0.000 & 1.000 \\
\hline Ano Eleitoral & 12609 & 0.315 & 0.465 & 0.000 & 0.000 & 1.000 & 1.000 \\
\hline Reeleito & 12605 & 0.333 & 0.471 & 0.000 & 0.000 & 1.000 & 1.000 \\
\hline Cobertura PBF & 12609 & 11.266 & 5.777 & 0.075 & 5.888 & 16.224 & 27.477 \\
\hline Votos Presidente & 12606 & 64.220 & 16.246 & 14.929 & 51.447 & 78.285 & 96.505 \\
\hline N Desastres & 12617 & 1.475 & 0.946 & 1 & 1 & 2 & 52 \\
\hline $\begin{array}{l}\text { N Declarações } \\
\text { Reconhecidas }\end{array}$ & 12617 & 1.155 & 0.869 & 0 & 1 & 2 & 6 \\
\hline $\begin{array}{l}\text { Transferência per } \\
\text { capita }\end{array}$ & 12617 & 7.784 & 53.550 & 0 & 0 & 0 & 1,922 \\
\hline Log População & 12609 & 9.573 & 1.173 & 6.712 & 8.725 & 10.193 & 16.285 \\
\hline
\end{tabular}

Fonte: Elaboração dos autores com base em dados do IBGE, Ministério do Desenvolvimento Regional, Ministério do Desenvolvimento Social e Tribunal Superior Eleitoral. 
Tabela A2

Alinhamento político e transferências federais de emergência

\begin{tabular}{|c|c|c|c|c|c|c|}
\hline & \multicolumn{6}{|c|}{ Variável dependente } \\
\hline & \multicolumn{3}{|c|}{ Transferência binária } & \multicolumn{3}{|c|}{ Log transferência per capita } \\
\hline & \multicolumn{3}{|c|}{ Logit } & \multicolumn{3}{|c|}{ OLS } \\
\hline & (1) & (2) & (3) & (4) & (5) & (6) \\
\hline Alinhamento Presidente & $\begin{array}{c}0.002 \\
(0.107)\end{array}$ & & & $\begin{array}{l}-0.201^{*} \\
(0.116)\end{array}$ & & \\
\hline Alinhamento Coalizão & & $\begin{array}{c}0.313^{* * *} \\
(0.085)\end{array}$ & & & $\begin{array}{l}-0.008 \\
(0.095)\end{array}$ & \\
\hline Alinhamento Ministro & & & $\begin{array}{l}0.285^{* *} \\
(0.116)\end{array}$ & & & $\begin{array}{c}0.217^{*} \\
(0.117)\end{array}$ \\
\hline Prop. Comissionado & $\begin{array}{l}-0.011^{*} \\
(0.006)\end{array}$ & $\begin{array}{l}-0.011^{*} \\
(0.006)\end{array}$ & $\begin{array}{l}-0.011^{*} \\
(0.006)\end{array}$ & $\begin{array}{l}0.026^{* * *} \\
(0.006)\end{array}$ & $\begin{array}{c}0.027^{* * *} \\
(0.006)\end{array}$ & $\begin{array}{l}0.026^{* * *} \\
(0.006)\end{array}$ \\
\hline Reeleito & $\begin{array}{l}-0.140^{*} \\
(0.078)\end{array}$ & $\begin{array}{l}-0.150^{*} \\
(0.078)\end{array}$ & $\begin{array}{l}-0.145^{*} \\
(0.078)\end{array}$ & $\begin{array}{c}-0.209^{* *} \\
(0.083)\end{array}$ & $\begin{array}{c}-0.208^{* *} \\
(0.083)\end{array}$ & $\begin{array}{c}-0.210^{* *} \\
(0.083)\end{array}$ \\
\hline Ano Eleitoral & $\begin{array}{c}2.185^{* * *} \\
(0.137)\end{array}$ & $\begin{array}{l}2.211^{* * *} \\
(0.137)\end{array}$ & $\begin{array}{c}2.148^{* * *} \\
(0.137)\end{array}$ & $\begin{array}{l}1.330^{* * *} \\
(0.176)\end{array}$ & $\begin{array}{l}1.336^{* * *} \\
(0.176)\end{array}$ & $\begin{array}{l}1.314^{* * *} \\
(0.176)\end{array}$ \\
\hline Cobertura PBF & $\begin{array}{c}-0.013 \\
(0.014)\end{array}$ & $\begin{array}{c}-0.012 \\
(0.014)\end{array}$ & $\begin{array}{c}-0.012 \\
(0.014)\end{array}$ & $\begin{array}{l}0.076^{* * *} \\
(0.015)\end{array}$ & $\begin{array}{c}0.079^{* * *} \\
(0.015)\end{array}$ & $\begin{array}{c}0.080^{* * *} \\
(0.015)\end{array}$ \\
\hline Votos Presidente & $\begin{array}{c}-0.021^{* * *} \\
(0.004)\end{array}$ & $\begin{array}{c}-0.022^{* * *} \\
(0.004)\end{array}$ & $\begin{array}{c}-0.021^{* * *} \\
(0.004)\end{array}$ & $\begin{array}{c}-0.006 \\
(0.004)\end{array}$ & $\begin{array}{c}-0.007 \\
(0.004)\end{array}$ & $\begin{array}{c}-0.006 \\
(0.004)\end{array}$ \\
\hline Estado Ministro & $\begin{array}{l}0.916^{* * *} \\
(0.203)\end{array}$ & $\begin{array}{l}0.918^{* * *} \\
(0.203)\end{array}$ & $\begin{array}{l}0.900^{* * *} \\
(0.203)\end{array}$ & $\begin{array}{c}0.269 \\
(0.324)\end{array}$ & $\begin{array}{c}0.280 \\
(0.326)\end{array}$ & $\begin{array}{c}0.217 \\
(0.326)\end{array}$ \\
\hline N Desastres & $\begin{array}{c}0.107^{* * *} \\
(0.032)\end{array}$ & $\begin{array}{c}0.107^{* * *} \\
(0.031)\end{array}$ & $\begin{array}{c}0.107^{* * *} \\
(0.032)\end{array}$ & $\begin{array}{c}-0.171^{* * *} \\
(0.049)\end{array}$ & $\begin{array}{c}-0.177^{* * *} \\
(0.049)\end{array}$ & $\begin{array}{c}-0.181^{* * *} \\
(0.049)\end{array}$ \\
\hline Efeitos Fixos (Ano) & SIM & SIM & SIM & SIM & SIM & SIM \\
\hline Efeitos Fixos (Estado) & SIM & SIM & SIM & SIM & SIM & SIM \\
\hline Constante & $\begin{array}{c}-1.260^{* *} \\
(0.518)\end{array}$ & $\begin{array}{c}-1.465^{* * *} \\
(0.520)\end{array}$ & $\begin{array}{c}-1.303^{* *} \\
(0.517)\end{array}$ & $\begin{array}{l}3.059^{* * *} \\
(0.547)\end{array}$ & $\begin{array}{l}3.052^{* * *} \\
(0.555)\end{array}$ & $\begin{array}{c}3.006^{* * *} \\
(0.547)\end{array}$ \\
\hline Observações & 12567 & 12567 & 12567 & 991 & 991 & 991 \\
\hline $\mathrm{R}^{2}$ & & & & 0.325 & 0.323 & 0.325 \\
\hline Adjusted $\mathrm{R}^{2}$ & & & & 0.300 & 0.297 & 0.300 \\
\hline Log Likelihood & $-2,651.570$ & $-2,644.661$ & $-2,648.629$ & & & \\
\hline Akaike Inf. Crit. & $5,379.140$ & $5,365.321$ & $5,373.258$ & & & \\
\hline $\begin{array}{l}\text { Residual Std. Error (df = } \\
954 \text { ) }\end{array}$ & & & & 1.209 & 1.211 & 1.209 \\
\hline F Statistic $(\mathrm{df}=36 ; 954)$ & & & & $12.765^{* * *}$ & $12.642^{* * *}$ & $12.783^{* * *}$ \\
\hline
\end{tabular}

Fonte: Elaboração dos autores com base em dados do IBGE, Ministério do Desenvolvimento Regional, Ministério do Desenvolvimento Social e Tribunal Superior Eleitoral.

Nota: $* p<0.1 ; * * p<0.05 ; * * * p<0.01$. 


\begin{abstract}
Politization of natural disasters: party alignment, emergency declarations, and allocation of federal resources to municipalities in Brazil

What is the relationship between party alignment and the allocation of federal recognition and emergency resources to Brazilian municipalities? We propose that even though disasters are given by nature, politics matter for federal recognition and the amount of transfers received. The argument is that the government will benefit the aligned mayors, recognizing the emergency declarations and allocating more resources to the municipalities of the same party. Considering the Brazilian coalition presidentialism, we tested three hypotheses for political alignment: alignment with the president, with the coalition, and with the minister of the portfolio. We present an original database with emergency declarations by the municipalities and the amounts transferred for that purpose in the period from 2010 to 2015 . We used Poisson regression models and a two-part model to test our hypotheses. The results indicate that declarations and emergency transfers are allocated in a way that benefits political allies at the subnational level, especially mayors aligned with the minister of the portfolio.
\end{abstract}

Keywords: natural disaster; coalition presidentialism; emergency declarations; federal emergency transfers

\title{
Resumen
}

Politización de desastres naturales: alineación de partes, declaraciones de emergencia y asignación de recursos federales a municipios en Brasil

¿Cuál es la relación entre la alineación del partido y la asignación de recursos por el gobierno y reconocimiento federal para los municipios brasileños? Proponemos que, aunque los desastres se den por naturaleza, la política es importante para el reconocimiento federal y la cantidad de transferencias recibidas. El argumento es que el gobierno beneficiará a los alcaldes alineados, reconociendo las declaraciones de emergencia y asignando más recursos a los municipios de la misma parte. Considerando el presidencialismo de la coalición brasileña, probamos tres hipótesis de alineamiento político: alineamiento con el presidente, con la coalición y con el ministro de la cartera. Presentamos una base de datos original con declaraciones de emergencia de los municipios y los montos transferidos para ese fin en el período de 2010 a 2015 . Utilizamos modelos de regresión de Poisson y en dos partes para probar nuestras hipótesis. Los resultados indican que las declaraciones y las transferencias de emergencia se asignan de una manera que beneficia a los aliados políticos a nivel subnacional, especialmente a los alcaldes alineados con el ministro de la cartera.

Palabras clave: desastre natural; presidencialismo de la coalición; declaraciones de emergencia; transferencias federales de emergencia

\section{Résumé}

La politisation des catastrophes naturelles: alignement des parties, déclarations d'urgence et attribution des ressources fédérales aux municipalités du Brésil

Quelle est la relation entre l'alignement des partis et l'allocation de la reconnaissance fédérale et des ressources d'urgence aux municipalités brésiliennes? Nous proposons que, même si les catastrophes sont attribuables à la nature, la politique compte pour la reconnaissance fédérale et le montant des transferts reçus. L'argument est que le gouvernement bénéficiera aux maires alignés, reconnaissant les déclarations d'urgence et allouant plus de ressources aux municipalités du même parti. Compte tenu du présidentialisme de la coalition brésilienne, nous avons testé trois hypothèses d'alignement politique: l'alignement avec le président, avec la coalition et avec le ministre du même domaine. Nous présentons une base de données originale avec les déclarations d'urgence des communes et les montants transférés à cet effet entre 2010 et 2015. Nous avons utilisé des modèles de régression de Poisson et en deux parties pour tester nos hypothèses. Les résultats indiquent que les déclarations et les transferts d'urgence sont alloués d'une manière qui profite aux alliés politiques au niveau infranational, en particulier aux maires alignés avec le ministre du même domaine.

Mots-clés: catastrophe naturelle; présidentialisme de la coalition; déclarations d'urgence; transferts d'urgence fédéraux

Artigo submetido à publicação em 22 de outubro de 2019. Versão final aprovada em 8 de setembro de 2020. Opinião Pública adota a licença Creative Commons CC-BY.

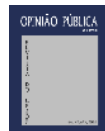

